\title{
Climatic impacts of fresh water hosing under Last Glacial Maximum conditions: a multi-model study
}

\author{
M. Kageyama ${ }^{1}$, U. Merkel ${ }^{2}$, B. Otto-Bliesner ${ }^{3}$, M. Prange ${ }^{2}$, A. Abe-Ouchi ${ }^{4}$, G. Lohmann ${ }^{5}$, R. Ohgaito ${ }^{6}$, D. M. Roche ${ }^{1}$, \\ J. Singarayer ${ }^{7}$, D. Swingedouw ${ }^{1}$, and X Zhang ${ }^{5}$ \\ ${ }^{1}$ LSCE/IPSL - Laboratoire des Sciences du Climat et de l'Environnement, UMR8212, CEA-CNRS-UVSQ - CE Saclay, \\ L'Orme des Merisiers, Bat. 701, 91191 Gif-sur-Yvette Cedex, France \\ ${ }^{2}$ MARUM - Center for Marine Environmental Sciences, University of Bremen, Klagenfurter Strasse, \\ 28334 Bremen, Germany \\ ${ }^{3}$ NCAR, National Center for Atmospheric Research, 1850 Table Mesa Drive, Boulder, Colorado 80305, USA \\ ${ }^{4}$ AORI, Atmosphere and Ocean Research Institute, University of Tokyo, 5-1-5 Kashiwanoha, Kashiwa, \\ Chiba 277-8568, Japan \\ ${ }^{5}$ Alfred Wegener Institute, Helmholtz Centre for Polar and Marine Research, Bussestr. 24, 27570 Bremerhaven, Germany \\ ${ }^{6}$ Japan Agency for Marine-Earth Science and Technology, Showa-machi 3173-25, Kanazawa, Yokohama, 236-0001, Japan \\ ${ }^{7}$ Department of Geographical Sciences, University of Bristol, University Road Bristol, BS8 1SS, UK
}

Correspondence to: M. Kageyama (masa.kageyama@1sce.ipsl.fr)

Received: 31 July 2012 - Published in Clim. Past Discuss.: 20 August 2012

Revised: 15 February 2013 - Accepted: 18 February 2013 - Published: 9 April 2013

\begin{abstract}
Fresh water hosing simulations, in which a fresh water flux is imposed in the North Atlantic to force fluctuations of the Atlantic Meridional Overturning Circulation, have been routinely performed, first to study the climatic signature of different states of this circulation, then, under present or future conditions, to investigate the potential impact of a partial melting of the Greenland ice sheet. The most compelling examples of climatic changes potentially related to AMOC abrupt variations, however, are found in high resolution palaeo-records from around the globe for the last glacial period. To study those more specifically, more and more fresh water hosing experiments have been performed under glacial conditions in the recent years. Here we compare an ensemble constituted by 11 such simulations run with 6 different climate models. All simulations follow a slightly different design, but are sufficiently close in their design to be compared. They all study the impact of a fresh water hosing imposed in the extra-tropical North Atlantic. Common features in the model responses to hosing are the cooling over the North Atlantic, extending along the sub-tropical gyre in the tropical North Atlantic, the southward shift of the Atlantic ITCZ and the weakening of the African and Indian monsoons. On the other hand, the expression of the bipo-
\end{abstract}

lar see-saw, i.e., warming in the Southern Hemisphere, differs from model to model, with some restricting it to the South Atlantic and specific regions of the southern ocean while others simulate a widespread southern ocean warming. The relationships between the features common to most models, i.e., climate changes over the north and tropical Atlantic, African and Asian monsoon regions, are further quantified. These suggest a tight correlation between the temperature and precipitation changes over the extra-tropical North Atlantic, but different pathways for the teleconnections between the AMOC/North Atlantic region and the African and Indian monsoon regions.

\section{Introduction}

Since their discovery in the North Atlantic marine sediment records and in the Greenland ice cores (Heinrich, 1988; Dansgaard et al., 1993), the abrupt events of the last glacial have been the topic of active research. On the palaeodata side, their climatic imprint was soon discovered to be of global extent (cf. the compilation by Voelker (2002) and the more recent review by Clement and Peterson (2008)), with 
signatures in the tropical hydrological cycle for the western tropical Atlantic (e.g., Peterson et al., 2000; Wang et al., 2004), for the East Asian monsoon (Wang et al., 2001), as well as in the Antarctic temperatures (e.g. EPICA community members, 2006). In particular, Antarctic temperature changes were shown to have a specific timing with respect to Greenland abrupt temperature changes, with warmings (respectively cooling) in Antarctica when Greenland is in a cool (respectively warm) state (Blunier and Brook (2001), confirmed by further works such as by the EPICA community members (2006)). This global expression of the glacial abrupt climatic events and the fact that the global ocean circulation was known to theoretically have multiple equilibria (Stommel, 1961) characterised by different climates (Manabe and Stouffer, 1988) pointed to the deep ocean circulation playing a major role in these events. The relative timings of Greenland vs. Antarctic temperature changes further confirmed this hypothesis which was formalised in the "bipolar see-saw" concept (Crowley, 1992; Stocker and Johnsen, 2003).

Fresh water hosing experiments, in which the Atlantic Meridional Overturning Circulation (AMOC) is perturbed by imposing a fresh water flux, usually in the North Atlantic, are useful numerical experiments to understand the mechanisms of climate change related to changes in AMOC. There are several motivations to perform such experiments. First, they are a way of characterising the stability of the AMOC, for a given model and a given set of boundary conditions. This can be done in a systematic manner by computing the hysteresis diagram of the AMOC strength reached at equilibrium for a range of fresh water hosing values (e.g. Rahmstorf, 1995), which can only be achieved with computationally efficient models, i.e., ocean models, as in Rahmstorf (1995), or Earth system models of intermediate complexity (EMICS, cf. Claussen et al., 2002), such as in Ganopolski and Rahmstorf (2001), Weber and Drijfhout (2007) or Lenton et al. (2007). These models show that there are different AMOC equilibrium states as a function of the fresh water flux, and that for specific boundary conditions/fresh water fluxes, there can be several AMOC equilibria. The state reached by the AMOC in such a case depends on the initial condition of the simulation. The fact that the AMOC shows multiple equilibria is important because each of these equilibria has a distinct climatic signature, as illustrated by Manabe and Stouffer (1988). Their model had two equilibria, one with a "vigorous" AMOC, the other with no AMOC. The "no AMOC" simulation showed a cooler North Atlantic ocean and cooler Nordic Seas and a stronger northern Hadley cell, with the ITCZ and associated zone of high precipitation shifted southward, particularly in the Atlantic. The potential for multiple equilibria of the AMOC associated with the climatic properties of these equilibria led to the hypothesis that the abrupt climatic changes recorded during glacial times could be explained by switches between the different equilibria.
In such a framework, the stability of a model's equilibrium is key to understanding the possibility of abrupt climate changes. Weber and Drijfhout (2007) show that in their model (ECBilt-CLIO), the characteristics of the stability of the AMOC depend on the transport of fresh water through the southern boundary of the Atlantic Ocean: the collapsed AMOC state is unstable for a northward transport and stable for the southward one. Using two versions of the GFDL general circulation model, Yin and Stouffer (2007) show that the properties of the thermohaline circulation in their AMOC weak state, as well as the amplitude of the tropical hydrological response and the fact that one of the model versions used flux corrections, are all important factors explaining the different AMOC stability properties of these model versions. Hence, the AMOC hysteresis diagram properties are specific to each model and even each model version. They are also sensitive to the experimental set-up and to the climate chosen as a base state. This was shown by Ganopolski and Rahmstorf (2001) with the CLIMBER-2 EMIC, for which the glacial state is characterised by a much narrower hysteresis of the AMOC compared to the pre-industrial state. This result was later corroborated employing a three-dimensional ocean general circulation model (Prange et al., 2002) and could explain the high sensitivity of the AMOC, and climate, under glacial conditions and, therefore, the occurrence of abrupt events preferentially in these glacial conditions.

Fresh water hosing experiments can also be used to mimic events in which there was a fresh water input to the ocean, for instance due to melt water associated with iceberg discharges during Heinrich events. In this case, the experiment is not specifically set up to characterise the different equilibria of the model, but rather to study the impact of hosing on the ocean circulation and global climate. Hosing is then typically applied for a few hundred years. This experimental set-up is, therefore, applicable to atmosphere-ocean general circulation models (AOGCMs) as well as EMICS. Such simulations have first been performed (e.g., Manabe and Stouffer, 1995, who used the GFDL coupled atmosphere-ocean general circulation model) in the present or pre-industrial contexts to highlight the climate changes associated with changes in AMOC. They are also motivated by the fact that most models appear to simulate a decrease in AMOC strength under increased atmospheric $\mathrm{CO}_{2}$ concentrations (Gregory et al., 2005; Weaver et al., 2012) and by the fact that the Greenland ice sheet could melt significantly in the future, which could have an impact on the AMOC and, therefore, modify the climate changes due to changes in atmospheric composition (Swingedouw et al., 2006). Even though these experiments are far from being run to equilibrium (which would take several millennia of simulation), they can give some information about the stability of the reference (unperturbed by fresh water) state, assuming this state is itself an equilibrium. This information can be obtained by studying whether the model returns to its reference state after the end of the fresh water perturbation, as is done, for instance, by Manabe 
and Stouffer (1995); Manabe and Stouffer (1997) or OttoBliesner and Brady (2010). Such hosing experiments, however, cannot give information about the climatic imprints of different equilibrium states, since the perturbed experiments are too short to allow a new equilibrium state to be reached. The response of the climate system to the fresh water hosing is then defined as a transient response, which can differ from the equilibrium response. This is illustrated in the recent review by Kageyama et al. (2010) from results of the UVic model, which shows that for the southern ocean, for instance, the transient response obtained after $500 \mathrm{yr}$ of a $0.2 \mathrm{~Sv}$ hosing in Saint Lawrence River outlet is much smaller than the full equilibrium response.

In their synthesis paper, Stouffer et al. (2006) compare the response of 9 AOGCMs and 5 EMICs to fresh water hosings of 0.1 and $1 \mathrm{~Sv}$ imposed for $100 \mathrm{yr}$ in the $50-70^{\circ} \mathrm{N}$ band of the North Atlantic in the modern climate. For the $0.1 \mathrm{~Sv}$ experiment, they find a decrease in AMOC ranging from 10 to $60 \%$. Common climatic responses in these simulations include North Atlantic cooling and a tendency for a southward shift of the Atlantic ITCZ. Some models simulate a northward shift of the Nordic Seas convection sites, which coincides with a warming to the north of the hosing area. The AMOC collapses (i.e., there is no mass or heat transport by the AMOC) in all models for a $1 \mathrm{~Sv}$ hosing. This collapse is not necessarily irreversible though, as most models do simulate an AMOC resumption a few hundred years after the end of the hosing. In the present work, we will use the term "collapse" in this sense, i.e., to characterise an AMOC which has vanished at a given time, but not necessarily irreversibly. By "collapse", we therefore do not imply a long-term, irreversible, collapse. In the synthesis of $1 \mathrm{~Sv}$ experiments presented by Stouffer et al. (2006), the climate response to hosing is larger than for the $0.1 \mathrm{~Sv}$ experiments, in terms of AMOC as well as in terms of climate, e.g., the southward shift of the ITCZ. Stouffer et al. (2006) highlight the common features of these hosing experiments, but note that the models' sensitivities to hosing, mostly evident from the $0.1 \mathrm{~Sv}$ hosing experiment, are different and that their climatic response can also be different in some regions such as the high-latitude Nordic Seas and the Arctic (in particular the Barents Sea). Since abrupt events have occurred throughout the last glacial period, palaeorecords might offer a way to evaluate the models' response to fresh water hosing.

However, the known abrupt events of the past have occurred in glacial conditions, which is a strong change in the boundary conditions compared to present ones. In a recent review on the climatic impacts of changes in AMOC, Kageyama et al. (2010) show differences between performing hosing experiments under pre-industrial and glacial base states by using two EMICs, LOVECLIM and UVic. They also highlight the impact of the different sensitivities of these models to hosing, in terms of AMOC, but also in terms of climate. In particular, the North Atlantic cooling signal is advected to the southern ocean if the AMOC remains active, which contrasts with the warming occurring for an AMOC collapse, following the classical bi-polar see-saw mechanism. In the present work, our main objective is to extend our initial study based on two EMICS to a wider range of models, including general circulation models. Indeed, a number of hosing experiments have been run under glacial boundary conditions and analysed since our review was written (cf. Table 2).

The precise climatic response to the details of the hosing scenario has been studied with the LOVECLIM EMIC by Roche et al. (2010). They test a range of hosing amplitudes for 10 different regions and find significant differences in the responses for Arctic vs. Nordic Seas hosing. This confirms earlier results from Manabe and Stouffer (1997) who show that for their model, a fresh water flux imposed in the Gulf of Mexico (mimicking a discharge via the Mississippi River) is much less efficient in triggering an AMOC decrease than a fresh water flux imposed in the North Atlantic. This could allow building climatic fingerprints characteristic of hosing in these regions and help constrain the hosing scenario for a given event. On the other hand, Otto-Bliesner and Brady (2010) find no large difference in the climatic response between the two hosing regions they test, i.e., the northern North Atlantic between 50 and $70^{\circ} \mathrm{N}$ and the Gulf of Mexico. Again, this calls for a comparison of model responses to fresh water flux scenarios, since we need to assess if these responses are model dependent before elaborating on possible triggering scenarios of abrupt climate changes.

Otto-Bliesner and Brady (2010) underscore that in their experiments, the ITCZ recovers simultaneously with tropical temperature, but much faster than the AMOC, northern seaice and Greenland temperatures. The relationship between climatic changes in the North Atlantic and those in the tropical areas will be investigated here from multiple model output. Indeed, one particularly intriguing and challenging aspect of the palaeodata from the times of abrupt changes is the remote teleconnections they suggest. Climatic changes in Europe, as characterised by pollen (Sánchez-Goñi et al., 2002) and speleothem (Genty et al., 2003) records have been connected to the Greenland climate changes. Further away, the ITCZ changes over the western tropical Atlantic (Cariaco Basin record, Peterson et al. (2000), vs. Northeast Brazil speleothem record, Wang et al. (2004)), dust records from the tropical East Atlantic (e.g. Jullien et al., 2007) and monsoon variations over China (e.g., the Hulu cave speleothem record of Wang et al., 2001), India (Leuschner and Sirocko, 2000) and Africa (Mulitza et al., 2008; Niedermeyer et al., 2009) have been correlated to the abrupt events recorded in Greenland and/or the North Atlantic. Understanding the mechanisms for these teleconnections is essential for gaining confidence in our simulations of abrupt climatic changes related to AMOC variations. This requires an assessment of the robustness of these teleconnections for different models, which we will address here. 
Table 1. Models compared in this analysis.

\begin{tabular}{|c|c|c|c|c|}
\hline $\begin{array}{l}\text { Experiment abbre- } \\
\text { viation }\end{array}$ & Model full name & Resolution & Reference & $\begin{array}{l}\text { Ocean sur- } \\
\text { face }\end{array}$ \\
\hline CCSM-NCAR & CCSM3 & $\begin{array}{l}\text { Atmosphere: T42L26; } \\
\text { Ocean } 1^{\circ}\end{array}$ & Collins et al. (2006) & free surface \\
\hline CCSM-MARUM & CCSM3 & $\begin{array}{l}\text { Atmosphere: T31L26; } \\
\text { Ocean } 3^{\circ}\end{array}$ & $\begin{array}{l}\text { Collins et al. (2006); } \\
\text { Yeager et al. (2006) }\end{array}$ & free surface \\
\hline MIROC-S & MIROC3.2 & $\begin{array}{l}\text { Atmosphere: T42L20; } \\
\text { Ocean } 1.4^{\circ}\end{array}$ & $\begin{array}{l}\text { K-1 model developers } \\
(2004)\end{array}$ & free surface \\
\hline MIROC-W & MIROC 3.2 & as above & Chikamoto et al. (2012) & as above \\
\hline IPSL & IPSL-CM4 & $\begin{array}{l}\text { Atmosphere: } \\
96 \times 72 \times 19 ; \quad \text { Ocean: } \\
2^{\circ}\end{array}$ & Marti et al. (2010) & free surface \\
\hline LCM10-0.15 & LOVECLIM & $\begin{array}{l}\text { Atmosphere:T21L3; } \\
\text { Ocean: } 3^{\circ}\end{array}$ & $\begin{array}{l}\text { Driesschaert et al. } \\
(2007)\end{array}$ & free surface \\
\hline LCM10-0.30 & as above & & & \\
\hline HadCM3-0.1 & HadCM3 & $\begin{array}{l}\text { Atmosphere: } \\
3.75 \times 2.5^{\circ} \\
\text { Ocean: } 1.25^{\circ}\end{array}$ & $\begin{array}{l}\text { Gordon et al. (2000); } \\
\text { Pope et al. (2000) }\end{array}$ & rigid lid \\
\hline HadCM3-0.4 & as above & & & \\
\hline COSMOS-S & COSMOS-aso & $\begin{array}{l}\text { Atmosphere:T31L19; } \\
\text { Ocean } 3 \times 1.8^{\circ}\end{array}$ & $\begin{array}{l}\text { Wei and Lohmann } \\
(2012)\end{array}$ & free surface \\
\hline COSMOS-W & as above & & & \\
\hline
\end{tabular}

Clement and Peterson (2008) provide an extensive review on the mechanisms for these teleconnections related to AMOC variations, based on the hosing experiments published at that time, i.e., mainly under present day conditions. They classify the simulated responses to fresh water hosing in three categories:

1. those showing symmetric adjustments in the northern extratropics by advection of the North Atlantic cooling by the mean westerlies, this cooling then propagating to the tropics through the wind-evaporation-SST (WES) feedback (Chiang et al., 2008) in all basins. This then acts to shift the ITCZ southward in all basins as well.

2. those simulating major changes in the North Atlantic, which propagate to the tropical Atlantic areas by atmospheric (e.g., again, by the WES feedback) and ocean processes. These changes in the tropical Atlantic then trigger contrasted responses in the other tropical basins by modifications of the Walker cells. The global response is zonally asymmetric.

3. those simulating fast oceanic teleconnections, related to wave propagation due to the sea-level height difference associated with the imposed fresh water flux in the North Atlantic.
From this review, we will record the zonally symmetric or asymmetric character of the response of models for fresh water hosing. Such a differentiation has also been highlighted by Dima and Lohmann (2010) for the recent evolution of the AMOC and climate.

Since the reviews by Clement and Peterson (2008) and Kageyama et al. (2010), many hosing experiments have been produced using glacial boundary conditions. Some of these have been published (Kageyama et al., 2009; Swingedouw et al., 2009; Otto-Bliesner and Brady, 2010; Merkel et al., 2010; Roche et al., 2010; Singarayer and Valdes, 2010), others are in the process of being published (Zhang et al., 2012). Our aim here is to take the opportunity offered by the availability of these results to compare them and assess the range of possible model responses to fresh water discharges. The objectives of each of these experiments were different, ranging from the sensitivity to hosing in different regions or to different hosing amplitudes (Roche et al., 2010; OttoBliesner and Brady, 2010) to the analysis of the impact of fresh water hosing on ENSO and its associated teleconnections (Merkel et al., 2010) or the impact of an AMOC collapse under a wide set of boundary conditions (Swingedouw et al., 2009; Singarayer and Valdes, 2010). It is, therefore, an ensemble which was not initially devised for a clean model 
intercomparison, but this ensemble gives a unique opportunity to compare model results for the glacial, as was done by Stouffer et al. (2006) for present conditions, albeit with a non pre-determined fresh water hosing set up. This set up and the AMOC response to the hosing are described in Sects. 2 and 3 , respectively.

Since the palaeorecords of abrupt climate changes are mostly palaeo-climate records, our main focus is on the climate changes to fresh water hosing, in relation to AMOC changes. We first characterise regions of agreement/disagreement between the climate responses in surface air temperature and precipitation to fresh water hosing by considering both the amplitude and the sign of the response (Sect. 4). We then attempt, for those regions with consistent responses across models, to quantify the relationships between the responses in temperature and precipitation over a given region, or between climate changes of different regions (Sect. 5) and to see if they are consistent with those found in previous works. In particular, we investigate the climatic changes over the North Atlantic, the tropical Atlantic, the African and Indian monsoon regions. Section 6 summarises our main findings and presents some perspectives to this first analysis.

\section{Description of the numerical simulations}

The comparison presented here is based on simulations that have been produced independently by 6 different palaeoclimate modelling groups, using 6 climate models, one of which (LOVECLIM) is a (rather complex) Earth System Model of Intermediate Complexity. A summary of the model characteristics and reference is provided in Table 1. The "MIROC-S" and "MIROC-W" experiments have been run using slightly different versions of the MIROC3.2 model (as described by Chikamoto et al., 2012, Sect. 2.2), which yield similar pre-industrial climates, but quite different LGM climates, in particular regarding the AMOC, which is strong $(19 \mathrm{~Sv})$ in the "MIROC-S" version and weak (8.4 Sv) in the "MIROC-W" version. The "COSMOS-S" and "COSMOSW" LGM reference simulations have been produced with the same version of the COSMOS model, but starting from different initial states, yielding very strong $(26.8 \mathrm{~Sv})$ and weaker (18.8 Sv) AMOCs (Zhang et al., 2012). The "CCSM-NCAR" and "CCSM-MARUM" experiments use the same model (CCSM3), but with different resolutions.

In total, we have analysed 11 sets of reference states/hosing experiments run with these 6 models. This is an "ensemble of opportunity" gathered from published (or existing, but not yet published) simulations. There was no common protocol decided in advance by all the groups, but we have endeavoured to gather experiments which were as close to each other as possible. Most groups have used the Last Glacial Maximum PMIP2 protocol (Braconnot et al., 2007, http://pmip2.lsce.ipsl.fr) for their reference simulation.
The HadCM3 experiments use the slightly different state of $24 \mathrm{kyr}$ BP (kyears before present). In terms of the ice-sheet distributions, atmospheric greenhouse gases and orbital parameters, this state only slightly differs from the $21 \mathrm{kyr} B P$ LGM state.

The "hosing" was applied as a fresh water flux over a large region of the North Atlantic (50-70 $\mathrm{N}$, "Ruddiman belt" or Greenland-Iceland-Norwegian Seas, cf. Table 2 for details) and not at the outlet of the Saint Lawrence River or in the Gulf of Mexico. In none of the experiments this fresh water hosing was compensated elsewhere on the globe. Its value ranges from 0.1 to $0.4 \mathrm{~Sv}$. The rationale behind this range was to use "realistic" values of hosing (compared to the other often used value of $1 \mathrm{~Sv}$, cf. Roche et al., 2004), but also to obtain states with weak AMOC and significant climatic responses even for models which proved not to be very sensitive to fresh water hosing: LOVECLIM and HadCM3 have a rather small response to fresh water hosing values of 0.15 and $0.1 \mathrm{~Sv}$, respectively. Therefore, for these models we have also analysed hosing simulations with stronger fresh water hosing values, which result in a stronger response in AMOC and climate.

The simulations had different durations and at times, the full time series were not available for all the experiments due to diverse technical reasons. This is why we could not analyse simulations for exactly the same periods after start of hosing. The period taken for analysis is, therefore, indicated in Table 2. The beginning of this period varies from 140 to $370 \mathrm{yr}$ after the start of hosing and its end from 150 and $419 \mathrm{yr}$ after the start of hosing. Most simulations were at equilibrium for the reference climate, but this is obviously not the case for the perturbed AMOC states, in particular, in terms of southern ocean or deep ocean temperatures. In other terms, the results shown here are transient responses to the corresponding fresh water perturbations. This is why we only briefly describe the AMOC response in the next section and we focus most of our analysis on the surface climatic response, attempting to characterise the relationship between climate and AMOC states, between different aspects of surface climate in one region (e.g., temperature vs. precipitation) and on the relationships between climate responses in different regions of the globe for which fast teleconnection mechanisms have been suggested by previous work, as briefly summarised in the introduction.

\section{Response of the Atlantic Meridional Overturning Circulation}

The range of results obtained for the $0.1 \mathrm{~Sv}$ hosing (Fig. 1) shows the diverse sensitivities of the models to fresh water hosing, with a nearly complete collapse for MIROC-S and IPSL. The COSMOS models also both simulate a complete collapse for a hosing of $0.2 \mathrm{~Sv}$. The CCSM AMOC anomalies do not appear as very large, but the AMOC in the reference 
Table 2. Brief description of the experiments compared in this analysis.

\begin{tabular}{|c|c|c|c|}
\hline $\begin{array}{l}\text { Experiment } \\
\text { abbreviation }\end{array}$ & Hosing experiment & $\begin{array}{l}\text { Years taken for } \\
\text { average }\end{array}$ & $\begin{array}{l}\text { Reference for the hosing } \\
\text { experiment }\end{array}$ \\
\hline CCSM-NCAR & $\begin{array}{l}0.1 \mathrm{~Sv} \text { (imposed as negative salinity flux) } \\
\text { for } 500 \mathrm{yr} \text { in North Atlantic, } 50-70^{\circ} \mathrm{N}\end{array}$ & $250-299$ & $\begin{array}{l}\text { Otto-Bliesner and Brady } \\
(2010)\end{array}$ \\
\hline $\begin{array}{l}\text { CCSM- } \\
\text { MARUM }\end{array}$ & $\begin{array}{l}0.2 \mathrm{~Sv} \text { (imposed as negative salinity flux) } \\
\text { in Greenland-Iceland-Norwegian Seas for } \\
360 \mathrm{yr}\end{array}$ & $\begin{array}{l}261-360 \text { for the AMOC, } \\
341-360 \text { for the climate } \\
\text { variables }\end{array}$ & Merkel et al. (2010) \\
\hline MIROC-S & $\begin{array}{l}0.1 \mathrm{~Sv} \text { (fresh water flux) in North Atlantic } \\
\left(50-70^{\circ} \mathrm{N}\right) \text { for } 500 \mathrm{yr}\end{array}$ & $370-419$ & \\
\hline MIROC-W & $\begin{array}{l}0.1 \mathrm{~Sv} \text { (fresh water flux) in North Atlantic } \\
\left(50-70^{\circ} \mathrm{N}\right) \text { for } 500 \mathrm{yr}\end{array}$ & $370-419$ & \\
\hline IPSL & $\begin{array}{l}0.1 \mathrm{~Sv} \text { (fresh water flux) in North Atlantic } \\
\left(50-70^{\circ} \mathrm{N}\right) \text { for } 419 \mathrm{yr}\end{array}$ & $370-419$ & Kageyama et al. (2009) \\
\hline LCM10-0.15 & $\begin{array}{l}0.15 \mathrm{~Sv} \text { in "Ruddiman Belt" (i.e., North } \\
\text { Atlantic, } 40-50^{\circ} \mathrm{N} \text { ) (fresh water flux) }\end{array}$ & $350-400$ & Roche et al. (2010) \\
\hline LCM10-0.30 & $\begin{array}{l}0.30 \mathrm{~Sv} \text { in "Ruddiman Belt" (fresh water } \\
\text { flux) }\end{array}$ & $220-240$ & Roche et al. (2010) \\
\hline HadCM3-0.1 & $\begin{array}{l}0.1 \mathrm{~Sv} \text { in North Atlantic }\left(50-70^{\circ} \mathrm{N}\right) \text {, im- } \\
\text { posed as a negative salinity flux, for } \\
1000 \mathrm{yr} \text {, reference experiment: } 24 \mathrm{kyr} \mathrm{BP}\end{array}$ & $270-299$ & $\begin{array}{l}\text { Singarayer and Valdes } \\
\text { (2010) for similar } 1 \mathrm{~Sv} \\
\text { hosing experiments and full } \\
\text { description of reference } \\
\text { experiment for } 24 \mathrm{kyr} \mathrm{BP}\end{array}$ \\
\hline HadCM3-0.4 & $\begin{array}{l}0.4 \mathrm{~Sv} \text { in North Atlantic }\left(50-70^{\circ} \mathrm{N}\right) \text {, im- } \\
\text { posed as a negative salinity flux, for } \\
1000 \mathrm{yr} \text {, reference experiment: } 24 \mathrm{kyr} \mathrm{BP}\end{array}$ & $270-299$ & $\begin{array}{l}\text { Singarayer and Valdes } \\
(2010)\end{array}$ \\
\hline COSMOS-S & $\begin{array}{l}0.2 \mathrm{~Sv} \text { (fresh water flux) in North At- } \\
\text { lantic (Ruddiman Belt) for } 150 \mathrm{yr} \text {, refer- } \\
\text { ence state: "strong" AMOC }\end{array}$ & $140-150$ & Zhang et al. (2012) \\
\hline COSMOS-W & $\begin{array}{l}0.2 \mathrm{~Sv} \text { (fresh water flux) in North Atlantic } \\
\text { Ruddiman Belt) for } 250 \mathrm{yr} \text {, reference state: } \\
\text { "weak" AMOC }\end{array}$ & $200-250$ & Zhang et al. (2012) \\
\hline
\end{tabular}

state for these models is rather small, so the relative decrease in AMOC for these models is quite large: $40 \%$ for CCSMNCAR, more than $60 \%$ for CCSM-MARUM. As explained in the previous section, HadCM3 and LOVECLIM had the weakest sensitivities to fresh water hosing, which is shown by the less than $30 \%$ decrease in AMOC for the hosing values of $0.1 \mathrm{~Sv}$ for HadCM3 and 0.15 Sv for LOVECLIM. Hosing experiments using stronger hosing amplitudes of 0.4 and $0.3 \mathrm{~Sv}$ were, therefore, included in this comparison. These result in a decrease in AMOC by nearly $70 \%$ for HadCM3 and by $80 \%$ for LOVECLIM.

The AMOC anomalies, whether absolute (Fig. 1c) or relative (Fig. 1d), generally do not correlate well with their reference values. The relationship appears to be linear for $0.1 \mathrm{~Sv}$ experiments, but there are too few of them (5) for these results to be unambiguous. Of course, the AMOC anomaly in response to hosing cannot be strong if the reference AMOC is weak (Fig. 1c). But collapse is obtained for reference states with strong (e.g. COSMOS-S) or quite weak (e.g. IPSL) AMOC (Fig. 1d)

In summary, we have a set of hosing experiments for full glacial states exhibiting a large range of AMOC responses to fresh water hosing, from small weakening to full collapse. In particular, two hosing experiments still have an active AMOC, even if it is weaker than in the reference state. Those simulations are HadCM3-0.1 and LCM10-0.15, for which the perturbed AMOC is larger than $10 \mathrm{~Sv}$ (absolute values of the AMOC are given on Figs. 2 and 4). CCSM-NCAR's perturbed AMOC, equal to $9.3 \mathrm{~Sv}$, is also close to this value. All other experiments exhibit a slow or nearly collapsed AMOC. 

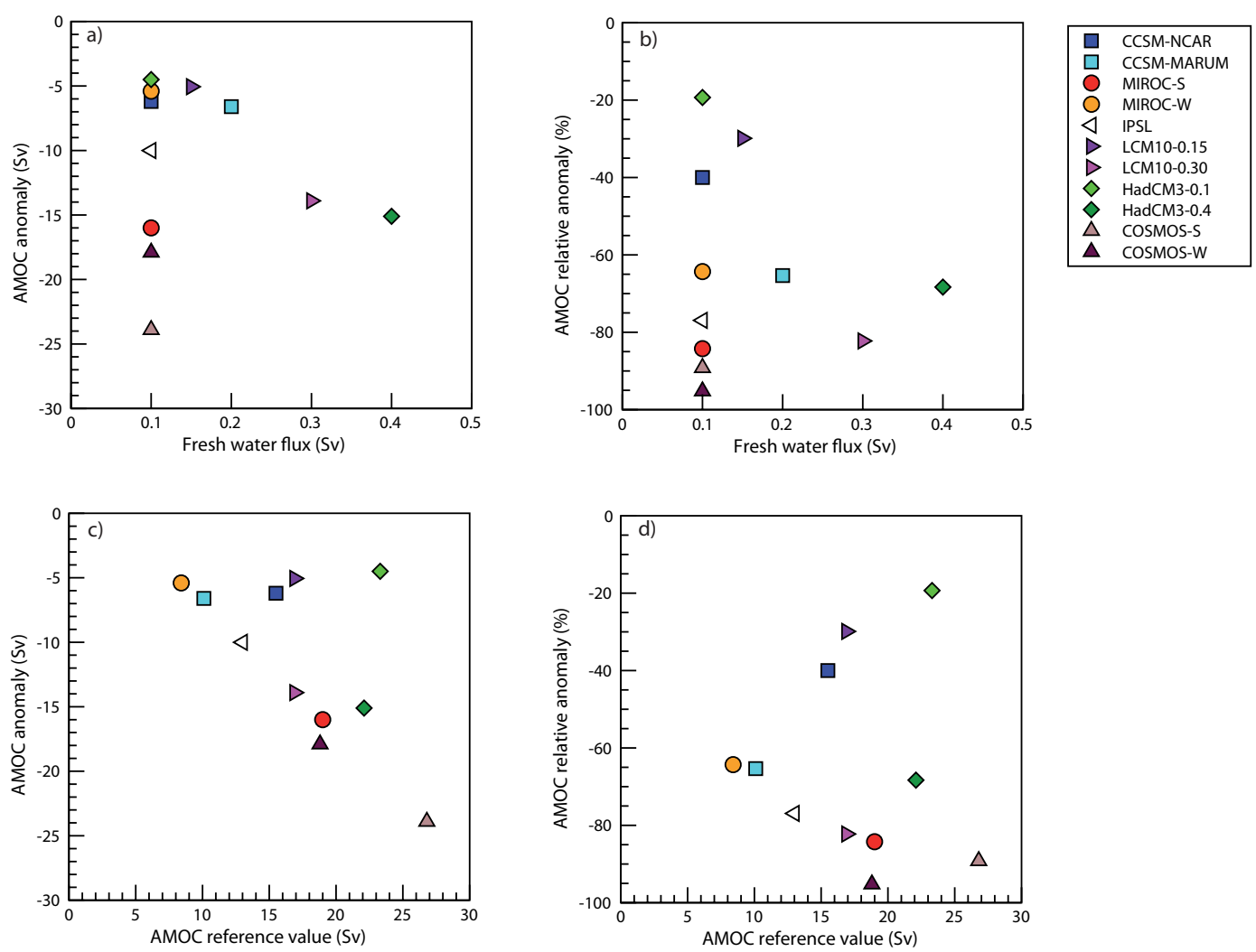

Fig. 1. Summary of AMOC behaviour in the different fresh water hosing simulations. The AMOC is defined as the maximum of the meridional streamfunction of the North Atlantic circulation in the Northern Hemisphere below $500 \mathrm{~m}$. The "AMOC anomaly" is defined as $\mathrm{AMOC}_{\mathrm{fw}}-\mathrm{AMOC}_{\mathrm{ref}}$, where $\mathrm{AMOC}_{\mathrm{ref}}$ is the value of the $\mathrm{AMOC}$ in the reference run and $\mathrm{AMOC}$ fw in the fresh water hosing run. The "AMOC relative anomaly", in \%, is defined as $100 \times\left(\mathrm{AMOC}_{\mathrm{fw}}-\mathrm{AMOC}_{\mathrm{ref}}\right) / \mathrm{AMOC}_{\mathrm{ref}}$.

\section{A global picture of the surface climate responses to fresh water hosing}

\subsection{Mean annual surface air temperature response}

As expected from the experimental design, all models produce their strongest mean annual surface air temperature response over the extra-tropical North Atlantic Ocean (Fig. 2). Cooling is also found in the Nordic Seas and the Arctic in all models. This contrasts with the results shown for the present climate in the comparison by Stouffer et al. (2006), for which warming was obtained in some of the models north of the hosing region due to a northward shift of the deep convection sites and amplification of its impact by the sea-ice changes through modulation of surface albedo and atmosphere-ocean heat fluxes. For a glacial state, this phenomenon does not seem to occur, which could be due to two factors: the deep convection sites are usually located more to the south and sea-ice is more extensive in LGM runs.

Although all models simulate a cooling over the North Atlantic extratropics, Nordic Seas and the Arctic Ocean in response to the fresh water perturbation, the magnitude of this cooling varies widely from model to model, as shown by the standard deviation of the mean annual temperature responses simulated in the ensemble of hosing experiments (Fig. 3 (top), all model results are regridded on the coarsest model grid (i.e., LOVECLIM) for the computation of the standard deviation and all experiments are considered with equal weight in this computation). The North Atlantic and the southern part of the Nordic Seas show a larger range of model responses, with a standard deviation reaching more than $5^{\circ} \mathrm{C}$. This range in model responses can also be seen from the individual model results (Fig. 2), in which the response of MIROC-W, with a cooling of around $2{ }^{\circ} \mathrm{C}$, contrasts with the larger than $7.5^{\circ} \mathrm{C}$ cooling simulated by e.g., CCSM-NCAR. Part of this large range in model response could be assigned to the range in AMOC responses to hosing, but another part could be attributed to the sea-ice extent in the reference state and the possible amplification of the hosinginduced cooling response by the sea-ice feedbacks. This amplification is strong in the CCSM-NCAR experiment, as explained by Otto-Bliesner and Brady (2010). It could be that the response of this model is rather strong because the reference LGM winter sea-ice over the western North Atlantic is quite extensive, as shown in comparison to other models by Kageyama et al. (2006) and Otto-Bliesner et al. (2007). 
Mean Annual Surface Air Temperature - anomaly Perturbed - Reference run

CCSM-NCAR AMOC ref: $15.5 \mathrm{~Sv}$ pert:9.3 Sv
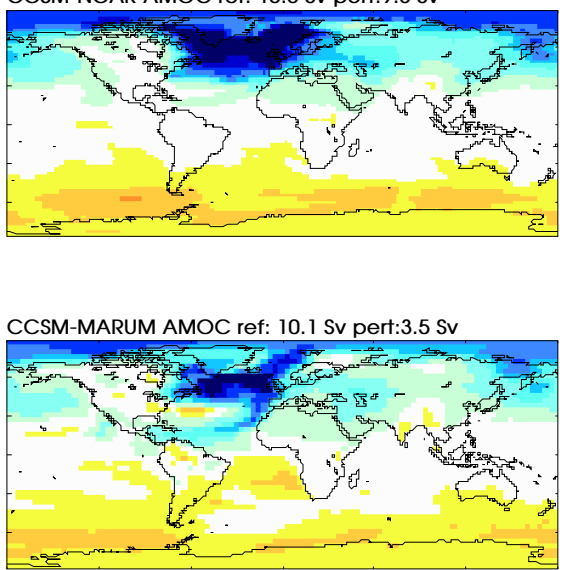

LCM10-0.30 AMOC ref: 16.9 Sv pert:3 Sv
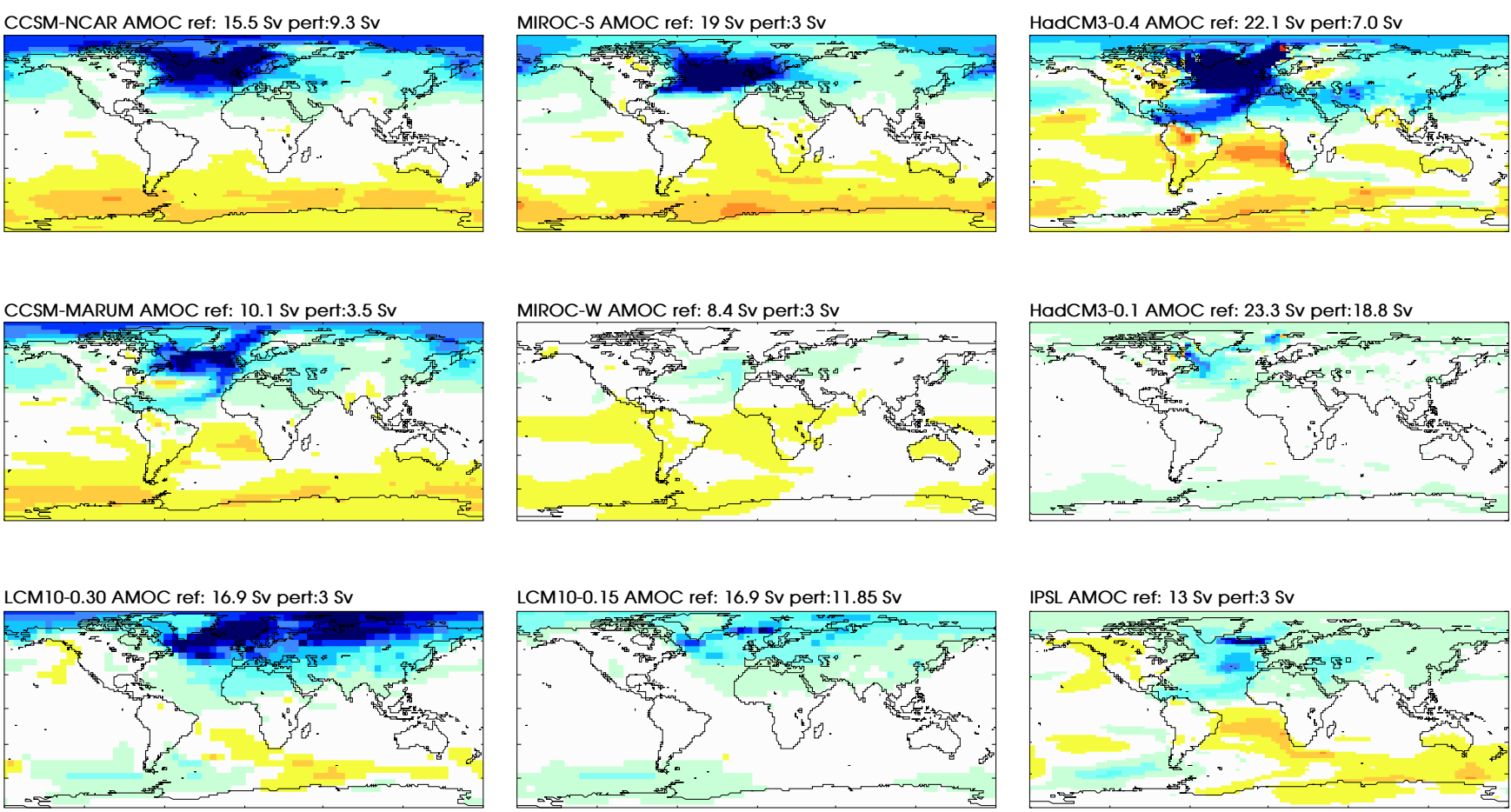

IPSL AMOC ref: $13 \mathrm{~Sv}$ pert:3 Sv

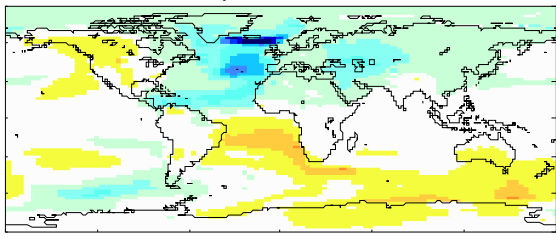

COSMOS-S AMOC ref: 26.8 Sv pert:2.9 Sv

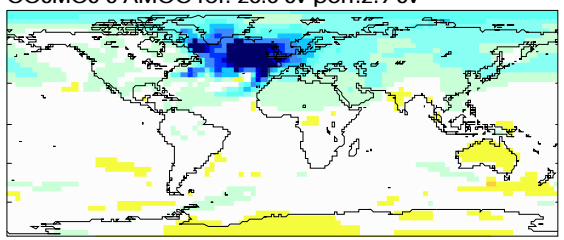

COSMOS-W AMOC ref: $18.8 \mathrm{~Sv}$ pert:0.9 Sv

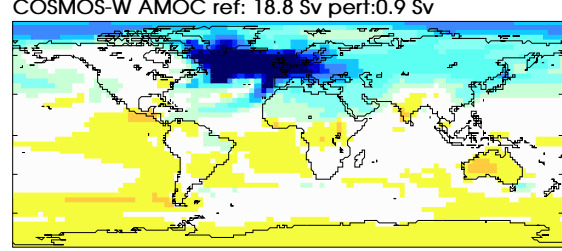

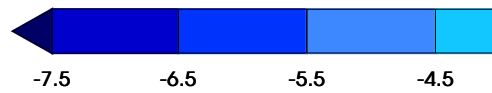
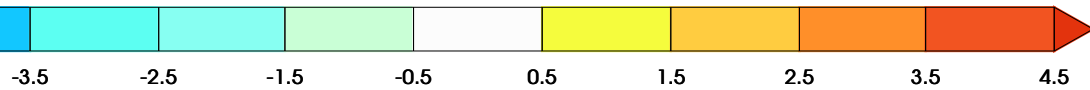

Fig. 2. Mean annual surface air temperature response (hosing experiment - reference experiment, in $\mathrm{K}$ ) to fresh water hosing in the 11 hosing experiments.

The cooling over the North Atlantic extratropics propagates along the Atlantic subtropical gyre, i.e., along the African west coast and then westward north of the equator. The extent of this propagation and the amplitude of the cooling signal are model dependent. Otto-Bliesner and Brady (2010) also point out that for the CCSM-NCAR model they are fresh water flux dependent. For instance, the cooling is very strong (up to $5^{\circ} \mathrm{C}$ in amplitude) and extends all the way to tropical America in HadCM3-0.4 while it does propagate to tropical America, but amounts to only $1{ }^{\circ} \mathrm{C}$ in CCSM-NCAR, despite the very strong cooling simulated by this model in the North Atlantic extra-tropics. Comparatively, the response of the MIROC-W model is nearly as strong over the tropics for a much weaker North Atlantic extratropical cooling.
Cooling is also consistently found by all models on at least some regions of Eurasia, as shown by the number of models simulating a temperature decrease larger than $0.5^{\circ} \mathrm{C}$ (Fig. 3 (bottom panel)). The simulated cooling is usually not uniform over the whole Eurasian continent and this diagnostic shows that the number of models simulating a cooling over Eurasia is maximum over a region around $60^{\circ} \mathrm{E}$. This corresponds to the fact that some models simulate less cooling, or, for HadCM3-0.1, even a small warming over Europe and that the cooling does not extend to the same longitude for all models. This feature of decreased cooling over Europe was observed in the IPSL_CM4 simulation by Kageyama et al. (2009) and attributed to a southwesterly wind anomaly associated with the North Atlantic cooling. This behaviour could also be present in other models, but unfortunately we did not 

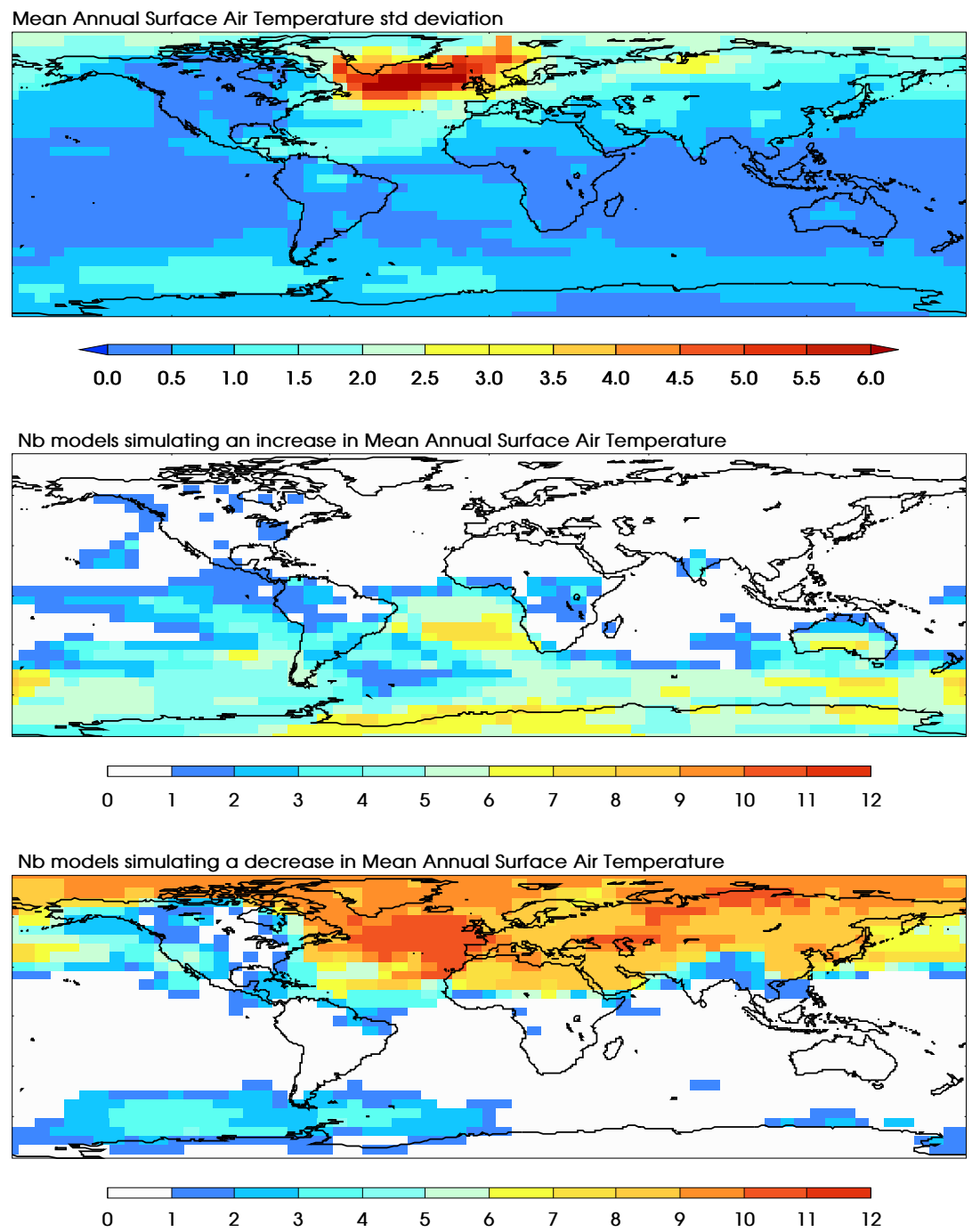

Fig. 3. (top) Standard deviation of the mean annual temperature responses to fresh water hosing simulated in the 11 hosing experiments (in $\mathrm{K}$ ); (middle) number of models showing an increase larger than $0.5 \mathrm{~K}$ between the perturbed and the reference experiments; (bottom) number of models showing a decrease larger than $0.5 \mathrm{~K}$ (in amplitude) between the perturbed and the reference experiments.

have the necessary atmospheric circulation fields to check this in the framework of the present comparison.

Over the rest of the Northern Hemisphere, and especially over the northeast Pacific and North America, no consistent cooling is simulated. This shows that the advection of the cold anomaly from the North Atlantic around the globe is not systematic for all models and that, as for Europe, potential impacts of atmospheric circulation changes (in particular of the planetary waves) can be important to set up the pattern of the thermal response to the AMOC decrease around the Northern Hemisphere. Analyses of these processes have not been undertaken yet and are left for further investigation.

Over the Southern Hemisphere, the expected response, at least for simulations in which the AMOC strongly decreases, is a warming of the South Atlantic ocean and of the southern ocean, i.e., the expression of the bi-polar see-saw. Fig- ures 2 and 3 show that this response is not as consistently simulated as the North Atlantic cooling. A majority of models do simulate a warming over the South Atlantic Ocean and some regions of the southern ocean (Indian Ocean sector, south of Australia and over the Southwest Pacific), but the results range from a few ${ }^{\circ} \mathrm{C}$ warming (CCSM-NCAR) to a few ${ }^{\circ} \mathrm{C}$ cooling (LCM10-0.30, LCM10-0.15, IPSL) over the Southeast Pacific. This is not surprising in experiments such as LCM10-0.15 or HadCM3-0.1, which retain an active AMOC. These are then able to transport the North Atlantic cooling anomaly to the Southern Hemisphere via the remaining global overturning circulation (cf., for instance, Duplessy et al., 2007; Renssen et al., 2010). In simulations in which the AMOC collapses, we can distinguish between models showing a warming on all longitudes of the southern ocean (e.g., CCSM-NCAR, MIROC-S) and others which 
Mean Annual Precipitation - anomaly Perturbed - Reference run
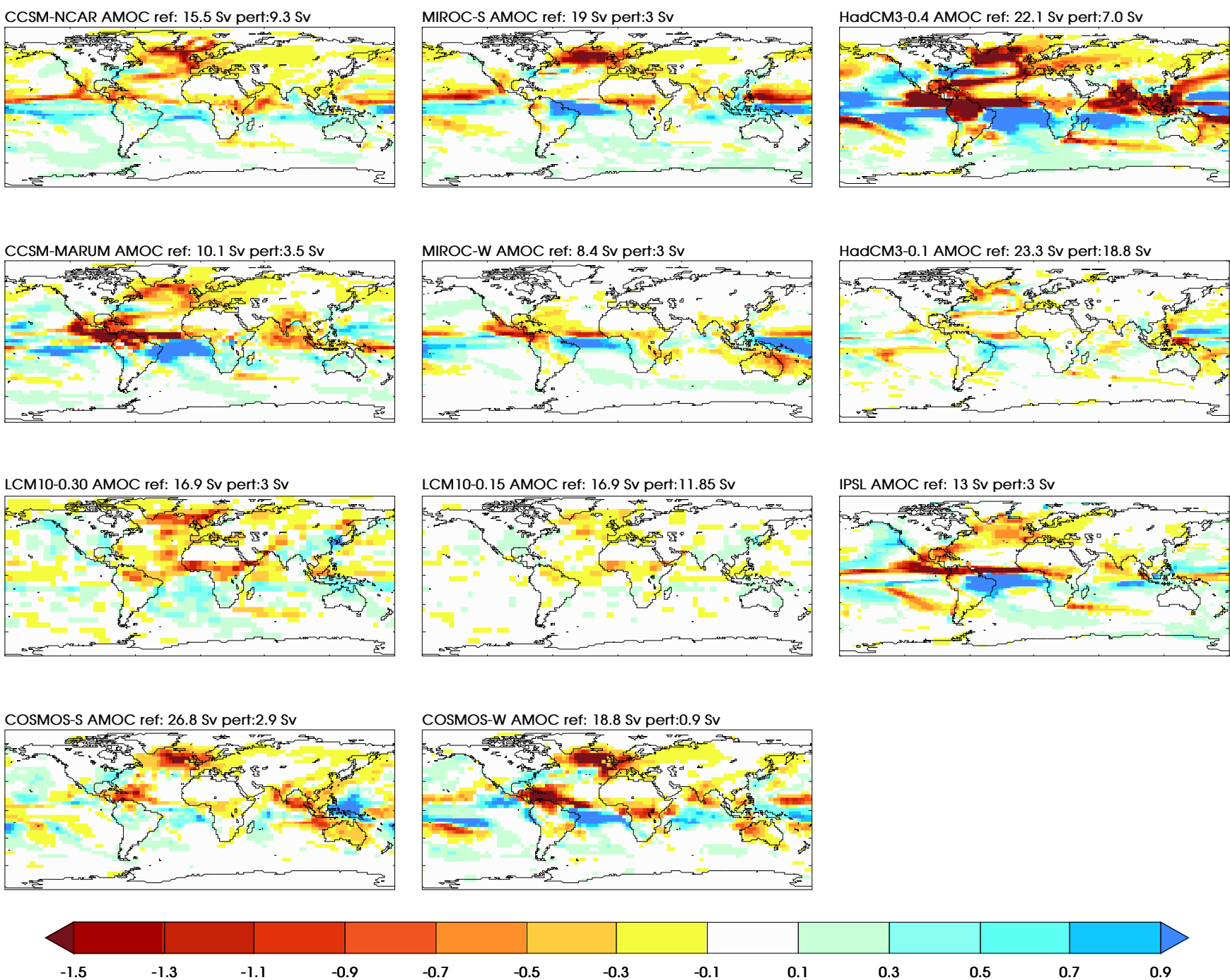

Fig. 4. Same as Fig. 2 for the mean annual precipitation, in $\mathrm{mm} \mathrm{day}^{-1}$.

display zonally asymmetric patterns, such as LCM10-0.30 or IPSL. The fact that warming is not consistently found for all longitudes of the southern ocean might be due to the available experiments being far from the equilibrium response and the warming associated with the bipolar see-saw needing time to propagate throughout the Southern Ocean. There could also be faster mechanisms which could prevent the establishment of a zonally homogeneous southern ocean warming. Buiron et al. (2012) suggest such a mechanism to be active in the IPSL_CM4 experiment, where cooling in the southeast Pacific is happening on timescales of a few decades as a result of a coupled atmosphere-surface ocean teleconnection with the tropical Atlantic. The southward shift of the ITCZ (cf. next section) over the tropical Atlantic appears to trigger this teleconnection.
In summary, as expected from the experimental design of the hosing simulations, the most consistent surface air temperature response across the models is the North Atlantic cooling, extending over much of extra-tropical Eurasia. The intensity of this cooling ranges from a couple of ${ }^{\circ} \mathrm{C}$ to more than $7.5^{\circ} \mathrm{C}$, but it proves difficult to relate the intensity of this cooling to the AMOC characteristics, as will be further shown in Sect. 5.1. The eastward extension over Eurasia and, downstream, over the Pacific, are very modeldependent and almost no model simulates a cooling over North America. However, we can distinguish experiments whose response in the northern extra-tropics is nearly zonal (at least in the sign of the response, CCSM-NCAR, CCSMMARUM, MIROC-S) from simulations in which it is clearly zonally asymmetric (IPSL, LCM10-0.15, LCM10-0.30). The "zonally symmetric" models are also those for which the 

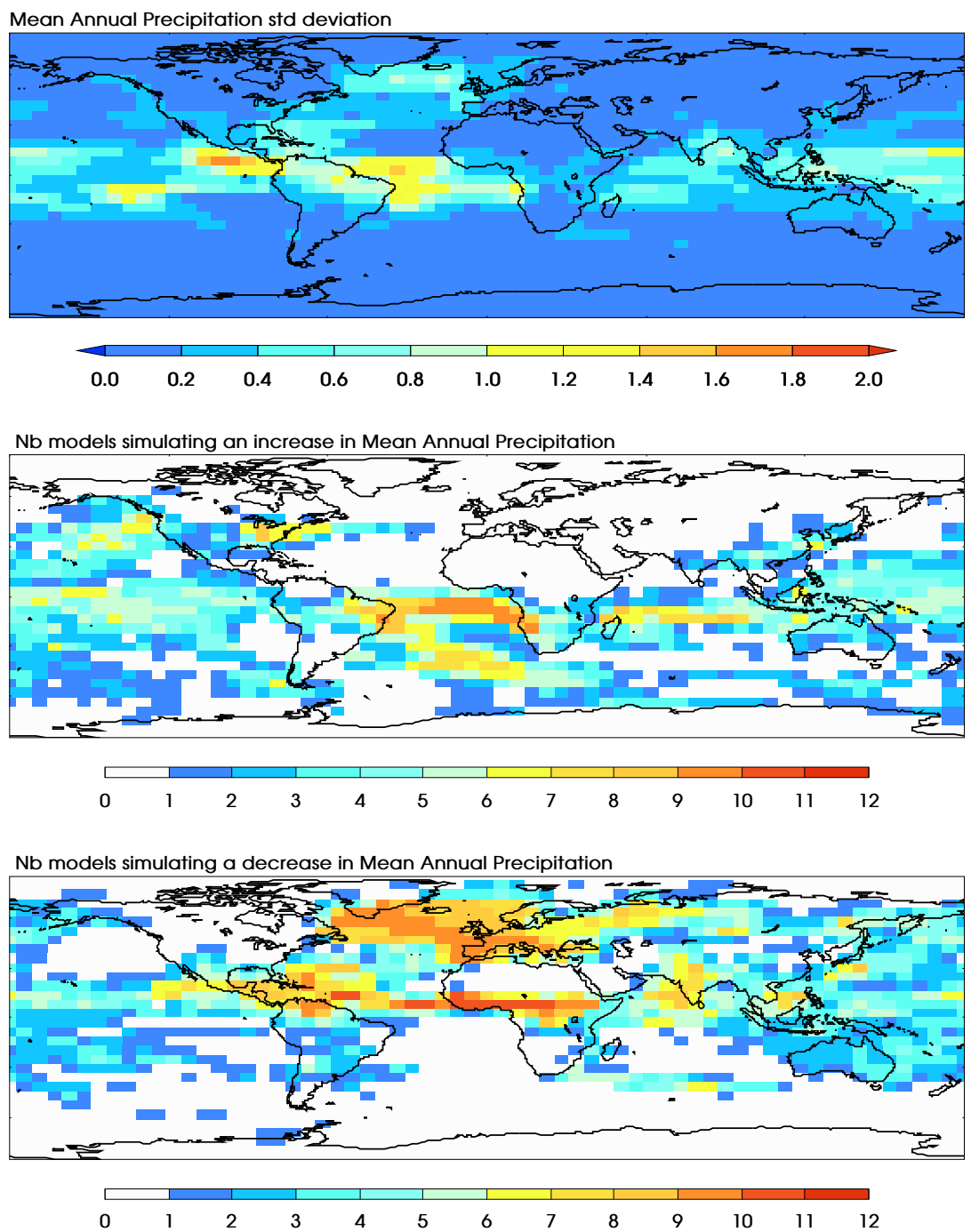

Fig. 5. Same as Fig. 3 for the mean annual precipitation (in $\mathrm{mm} \mathrm{day}^{-1}$ for the top panel).

warming is most extensive and strongest over the southern ocean. For this region, there is less consistency, even in sign, of the model responses to hosing in the North Atlantic. Zonal aysmmetries and for some models cooling in some regions of the southern ocean, are inconsistent with the traditional view of the bi-polar see-saw. This could only be a transient response or the result of faster atmosphere-surface ocean teleconnections from the tropics. To distinguish between those, we would need much longer experiments which were not available for all models for this comparison exercise.

\subsection{Mean annual precipitation response}

Over the North Atlantic, the precipitation decreases for all models (Fig. 4), consistently with the temperature decrease (Fig. 2). This is consistent with the Clausius-Clapeyron relationship, but also with the fact that a more extensive sea-ice cover prevents evaporation. The relationship between precip- itation and temperature changes will be further analysed in Sect. 5.1.

Nearly all models show an increase in precipitation over the tropical Atlantic south of the equator, while they show a decrease in precipitation just north of the equator and in the African monsoon region (Fig. 5). Most models, therefore, simulate a southward shift of the Atlantic ITCZ, even those with modest AMOC weakening. The atmospheric component of the LOVECLIM model being based on a quasi-geostrophic formulation, the tropical/equatorial atmospheric circulation is not very well represented in this model. Therefore, the precipitation response is not very clear for the LCM10-0.15 simulation (weak AMOC decrease). It is nonetheless surprisingly clear in the LCM10-0.30 run (strong AMOC reduction), for which the precipitation response associated with the ITCZ southward shift and decrease in the African monsoon diagnosed in the other models can be recognised for this EMIC too. The ITCZ southward shift 

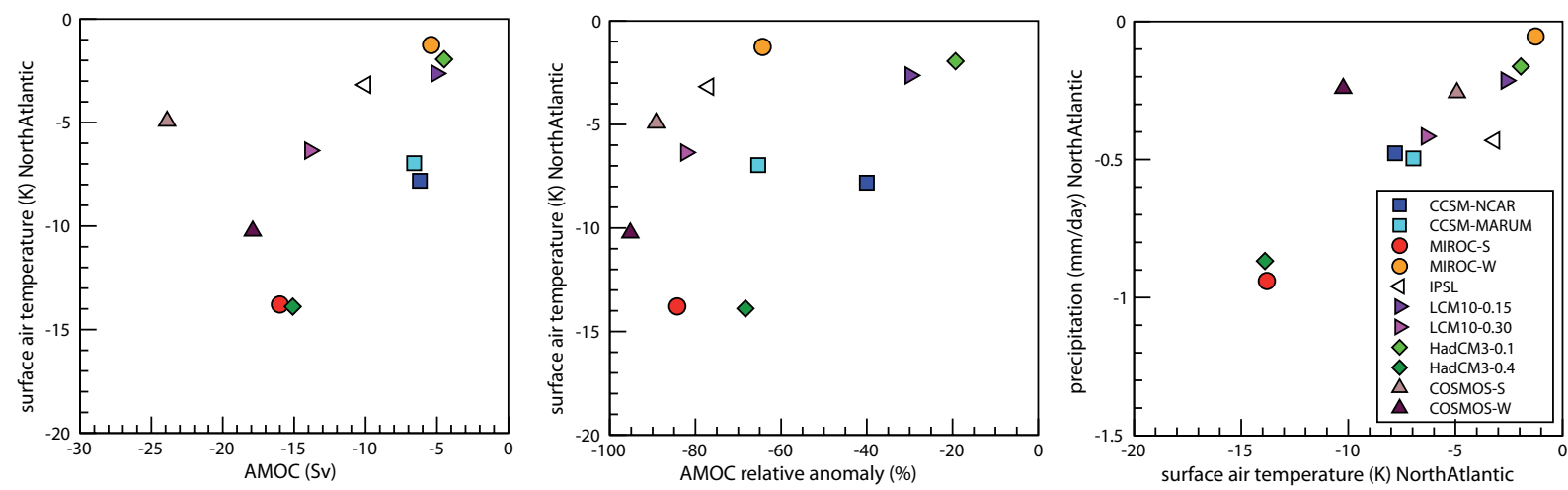

Fig. 6. Relationships for the North Atlantic extratropics, (1.h.s) between the changes (related to hosing) in mean annual surface air temperature averaged over this region and the AMOC changes, (middle panel) between the same temperature changes and the AMOC relative changes and (r.h.s) between the changes in mean annual temperatures and mean annual precipitation averaged over this region. The region for the area average is defined for longitudes between 50 and $10^{\circ} \mathrm{W}$ and latitudes between 40 and $60^{\circ} \mathrm{N}$.

extends to other tropical regions in some of the models, especially those which showed a strong extra-tropical temperature response outside the Atlantic region. The response over the tropical Pacific Ocean is, however, quite model dependent since the maps for the number of models simulating an increase or decrease in precipitation (Fig. 5) do not show any consistent pattern there.

The Indian monsoon appears to weaken in most of the model experiments with a strong AMOC decrease, with the exception of the LOVECLIM model which is not well suited to resolve this particular feature. This consistent response is quite remarkable given the number of factors which can affect the Indian monsoon and given the fact that this climatic feature is of smaller scale compared to the other features discussed in this section.

In the following section, we investigate potential relationships between these changes in precipitation and the temperature changes described in Sect. 4.1.

\section{An attempt at quantifying the relationships between the responses of $\mathrm{AMOC}$, temperature and precipita- tion, to fresh water hosing}

Here we study the relationship between AMOC changes and averages of the temperature and precipitation anomalies over key regions, defined as follows:

- the "NorthAtlantic" (extra-tropical North Atlantic): 50$10^{\circ} \mathrm{W}, 40-60^{\circ} \mathrm{N}$;

- the "NorthTropicalAtlantic": 50-15 $5^{\circ} \mathrm{W}, 5-30^{\circ} \mathrm{N}$;

- the "NorthEqAtlantic" $\left(10^{\circ}\right.$ latitudinal band of the NorthTropicalAtlantic region closest to the equator): $50-15^{\circ} \mathrm{W}, 5-15^{\circ} \mathrm{N}$;

- the "SouthTropicalAtlantic": $30^{\circ} \mathrm{W}-10^{\circ} \mathrm{E}, 20^{\circ} \mathrm{S}-5^{\circ} \mathrm{N}$;
- "Africa" (region of the African monsoon): $15^{\circ} \mathrm{W}-$ $15^{\circ} \mathrm{E}, 5-15^{\circ} \mathrm{N}$;

- "India" (region of the Indian monsoon): $60-90^{\circ} \mathrm{E}, 10-$ $30^{\circ} \mathrm{N}$;

- the "IndianOcean" : $50-100^{\circ} \mathrm{E}, 10^{\circ} \mathrm{S}-15^{\circ} \mathrm{N}$.

\subsection{The North Atlantic}

As we have seen in Sect. 4.1, the most consistent impact of hosing, found in all models, is the cooling of the North Atlantic Ocean in the extra-tropics. However, the amplitude of this cooling is only vaguely related to both the AMOC absolute (Fig. 6, 1.h.s) or relative (Fig. 6, middle panel) decrease. This shows that other factors come into play to explain this amplitude: temperatures and the presence of sea-ice in the reference state, or a large change in sea-ice cover between the hosing and the reference experiments, are good candidates which unfortunately we could not test from the available data. A better understanding of the temperature changes over this region could also be obtained through the analysis of changes in oceanic heat transport in relation with the AMOC changes. These heat transports were unfortunately not available for all models.

A much better relationship is found between temperature and precipitation changes (Fig. 6, r.h.s) over the North Atlantic region. If we exclude the result from the COSMOS-W experiment, the relationship is even nearly linear, with precipitation changes ranging from nearly zero to $-1 \mathrm{~mm} \mathrm{day}^{-1}$ for temperature changes ranging from -1 to $-14^{\circ} \mathrm{C}$. The COSMOS-W relatively weak decrease in precipitation compared to its strong cooling can be explained by the fact that in the southern part of the region on which the "North Atlantic" average is computed, precipitation is actually simulated to increase (Fig. 4). This behaviour is also found for other models such as in experiments CCSM-NCAR, CCSM-MARUM and HadCM3-0.4 and is consistent with a southward shift of 

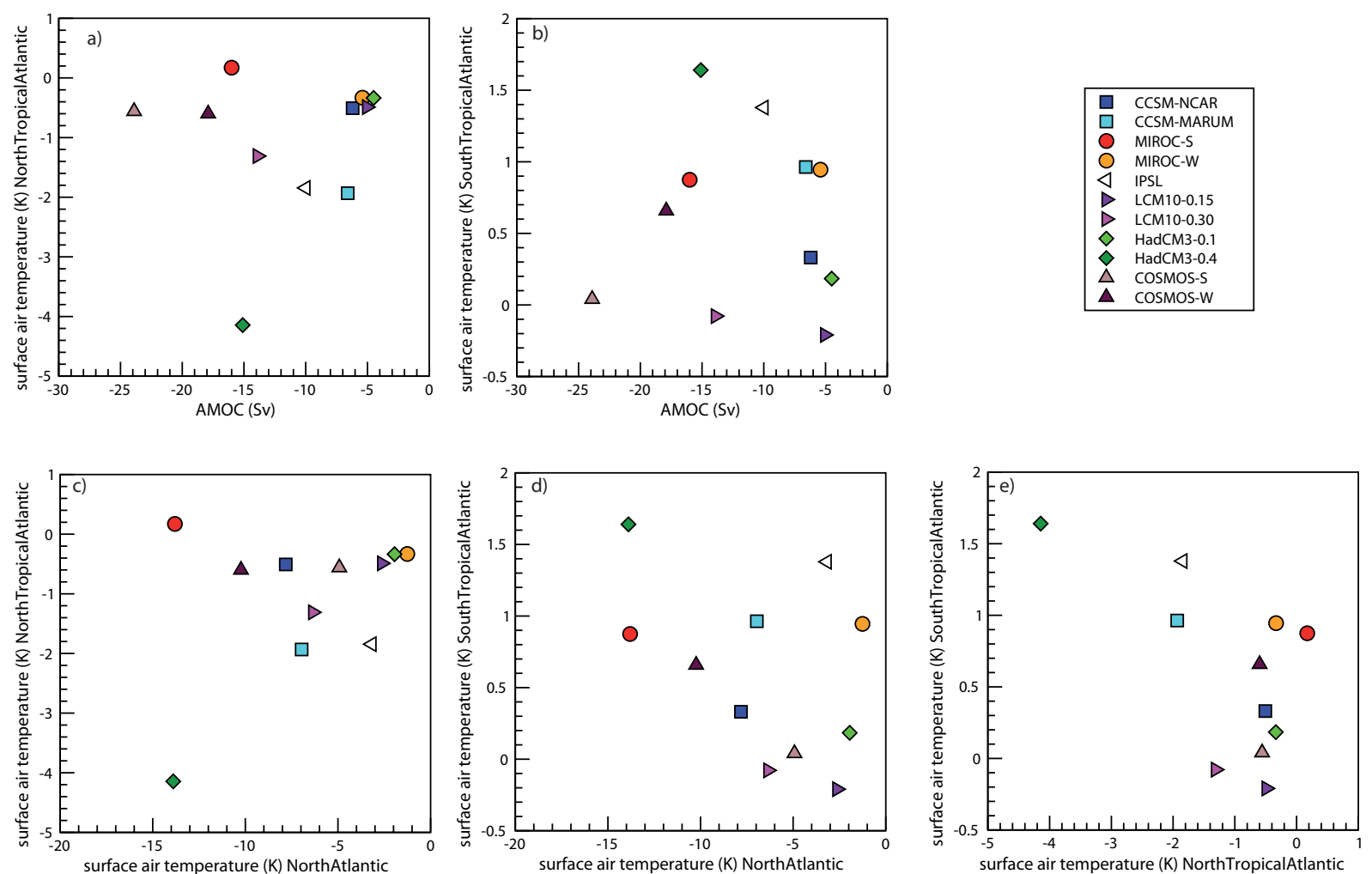

Fig. 7. Relationships involving tropical Atlantic temperature changes related to fresh water hosing. The "NorthTropicalAtlantic" region is defined as the region with latitudes between 5 and $30^{\circ} \mathrm{N}$ and longitudes between 50 and $15^{\circ} \mathrm{W}$. The "SouthTropicalAtlantic" region is defined as the region with latitudes included between $20^{\circ} \mathrm{S}$ and $5^{\circ} \mathrm{N}$ and longitudes between $30^{\circ} \mathrm{W}$ and $10^{\circ}$ E. Top: relationships between temperature changes over these regions and AMOC relative changes. Bottom: (left and middle) relationships between temperature changes over these regions and the NorthAtlantic (region defined in Fig. 6) temperature changes; (right) relationship between the temperature changes over the NorthTropicalAtlantic and SouthTropicalAtlantic regions.

the Atlantic storm-track, which could be related to the southward displacement of the mid-latitude thermal front. The region of precipitation increase is, however, narrower in these other models than in COSMOS-W.

\subsection{The tropical Atlantic}

As for the mid-latitude North Atlantic, there is no systematic relationship between the AMOC changes (whether absolute, as shown on Fig. 7, top panels, or relative, not shown) and the temperature changes over the northern and southern tropical Atlantic (Fig. 7, bottom panels). We then investigate if there is any relationship with the NorthAtlantic extratropical temperature changes (the "NorthAtlantic" region defined in the same way as above), as could happen through mechanisms such as the WES feedback (cf. Introduction). Figure 7c shows little correlation between NorthTropicalAtlantic and NorthAtlantic coolings, as was suggested by visual inspection of the temperature difference maps from Fig. 2. This suggests that the WES feedback strength could differ from model to model or that other mechanisms come into play, e.g. oceanic processes such as the feedback of a tropical
Atlantic salinity anomaly on the AMOC (e.g., Mignot and Frankignoul, 2010). Understanding why the models differ in their northern extratropical vs. tropical surface temperature relationship would require many more variables than those gathered for this first comparison, e.g., evaporation, surface winds, ocean mixed layer and currents and heat transports by the atmosphere and the ocean. Such an analysis is, therefore, left for future investigation. There is no strong correlation between NorthAtlantic and SouthTropicalAtlantic coolings either (Fig. 7d) except that no weak SouthTropicalAtlantic warming is obtained for strong NorthAtlantic cooling. This explains that there is little correlation between NorthTropicalAtlantic and SouthTropicalAtlantic temperature changes (Fig. 7e).

We then investigate changes in tropical Atlantic precipitation (Fig. 8). For the northern side of the equator, we have computed averages over a more restricted region (labelled "NorthEqAtlantic") than for the temperatures because precipitation changes are restricted to the southern part of the NorthTropicalAtlantic region used in Fig. 7. Precipitation changes on the northern and southern side of the equator are anti-correlated, with the strongest increase in precipitation 

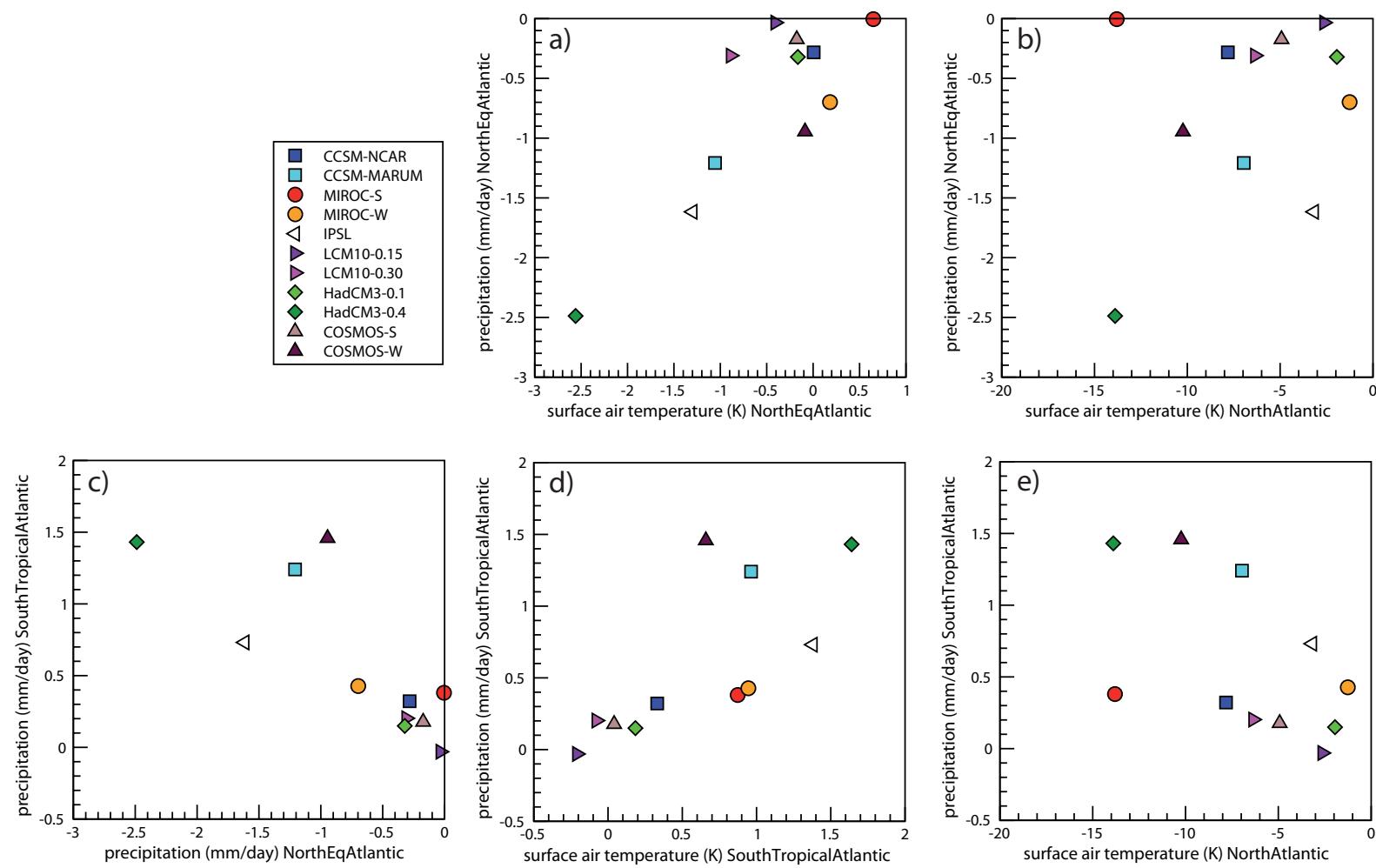

Fig. 8. Relationships involving tropical Atlantic precipitation changes related to fresh water hosing: (a) between the precipitation and temperature changes over the NorthEqAtlantic region, defined as the region with latitudes ranging between 5 and $15^{\circ} \mathrm{N}$ and longitudes between 50 and $15^{\circ} \mathrm{W}$; (b) between the NorthEqAtlantic precipitation changes and the NorthAtlantic (as defined in Fig. 6) temperature changes, (c) between the precipitation changes over the SouthTropicalAtlantic and the NorthEqAtlantic region, (d) between the precipitation and temperature changes over the SouthTropicalAtlantic region defined as in Fig. 7, (e) between the SouthTropicalAtlantic precipitation changes and the NorthAtlantic emperature changes.

south of the equator occurring for models which also simulate the strongest decrease in precipitation north of the equator (Fig. 8c). Taken individually, precipitation changes over these regions correlate reasonably well with the underlying temperature changes (Fig. 8a and d). Given the absence of relationship between North Atlantic temperature changes and tropical temperature changes over the tropical Atlantic both north (Fig. 7c) and south (Fig. 7d) of the equator, it is not surprising to see no consistency between North Atlantic extratropical temperature changes and tropical precipitation changes north or south of the equator either (Fig. 8b and e).

In summary, the changes in tropical precipitation over the northern and southern tropical Atlantic correlate well with the underlying temperature changes. The precipitation changes north and south of the equator are anti-correlated, confirming a southward shift of the ITCZ. These changes, however, do not appear to be strongly correlated to either the AMOC changes or the North Atlantic extratropical temperature changes, indicating that the extra-tropical - tropical connections are model dependent.

\subsection{The African and Indian monsoons}

The mean annual precipitation over the African monsoon region was shown to consistently decrease in most models (Fig. 5). Figure 9 attempts to quantify the relationships between the precipitation changes simulated over this region and surface temperature changes over the key regions investigated so far. This figure shows that it is actually very difficult to find a consistent relationship with temperature changes over any of these regions (NorthAtlantic, NorthTropicalAtlantic, NorthEqAtlantic and SouthTropicalAtlantic).

Further away from the Atlantic, the Indian monsoon region also showed a consistent decrease in precipitation among the models. Figure 10 shows that there is little correlation between these precipitation changes and the Indian Ocean temperature changes (Fig. 10d), nor with the NorthTropicalAtlantic changes (Fig. 10b). The correlation improves for the NorthAtlantic extratropical temperature changes (Fig. 10a), albeit with a large dispersion for strong NorthAtlantic coolings. The best correlation is obtained with temperature changes over the SouthTropicalAtlantic region (Fig. 10c). The relationship could be nonlinear, with 

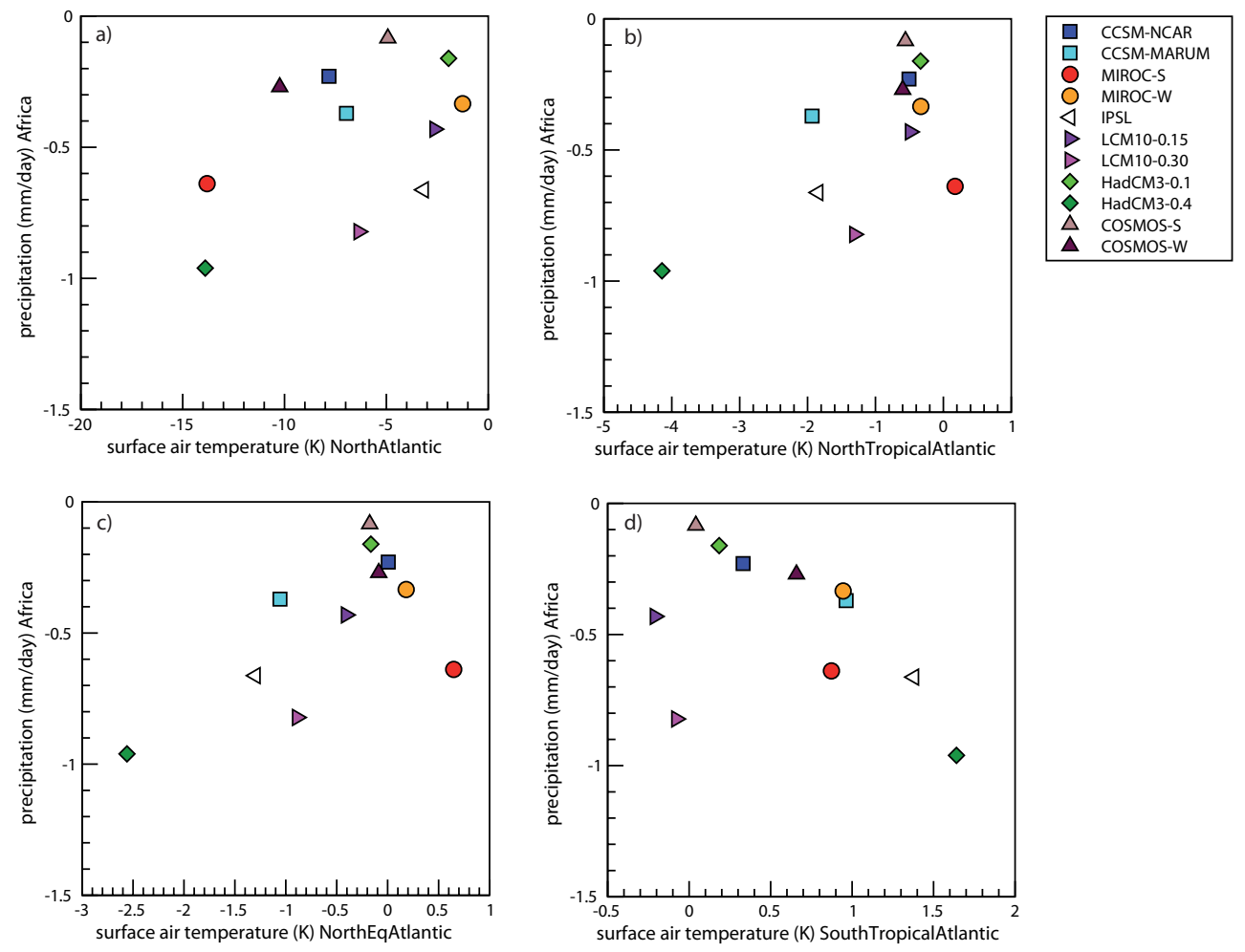

Fig. 9. Relationships involving precipitation changes over the African monsoon region, defined for latitudes between 5 and $15^{\circ} \mathrm{N}$ and longitudes between $15^{\circ} \mathrm{W}$ and $15^{\circ} \mathrm{E}$; (a) with NorthAtlantic temperatures, (b) with NorthTropicalAtlantic temperatures, (c) with NorthEqAtlantic temperatures and (d) with SouthTropicalAtlantic temperatures.

precipitation decrease over the Indian monsoon region getting stronger for stronger warming over the SouthTropicalAtlantic region, although admittedly this conclusion would be hard to sustain without the strong response of the HadCM30.4 model. These relationships suggest a tropical pathway in the response of the Indian monsoon to fresh water hosing. Marzin et al. (2012) actually find such a pathway by performing sensitivity experiments to the North Atlantic extratropical vs. tropical Atlantic SST changes due to fresh water hosing with the IPSL model. They argue that the tropical SST changes are an efficient way of pulling the subtropical jet-stream southward over Africa and downstream, which results in a cooling of upper-tropospheric temperatures over the Tibetan plateau and finally in a weakening of the Indian monsoon. It would be interesting, if we had the wind fields and the upper temperature fields for each model, to check whether this mechanism occurs here, but at least the relationship between the SouthTropicalAtlantic temperature changes and the changes over the Indian monsoon region is consistent with this explanation.

\section{Conclusions}

In this work, we performed a first comparison of fresh water hosing experiments run under full glacial conditions. We compared 6 models and 11 sets of simulations in total. These were not run with the specific objective of performing this comparison, which resulted in a restricted variable list being available for analysis.

The main conclusions from our comparison can be summarised as follows:

- The AMOC response to a $0.1 \mathrm{~Sv}$ fresh water flux imposed in the North Atlantic varies from a very small decrease to nearly a collapse. This range is much larger than the results obtained for the pre-industrial base state comparison of Stouffer et al. (2006). This suggests different sensitivities of the pre-industrial and LGM base states, but we would need a dedicated ensemble of preindustrial and LGM hosing experiments run with exactly the same models to further compare the sensitivities of these climate states and analyse the reasons for their differences.

- The regions with consistent behaviour in their response to fresh water hosing are: the North Atlantic for temperatures and precipitation which both decrease, and for precipitation the tropical Atlantic (southward shift of the ITCZ), the African and Indian monsoon regions (with a decrease in precipitation). This is in line with palaeoclimatic evidence of abrupt events occurring 

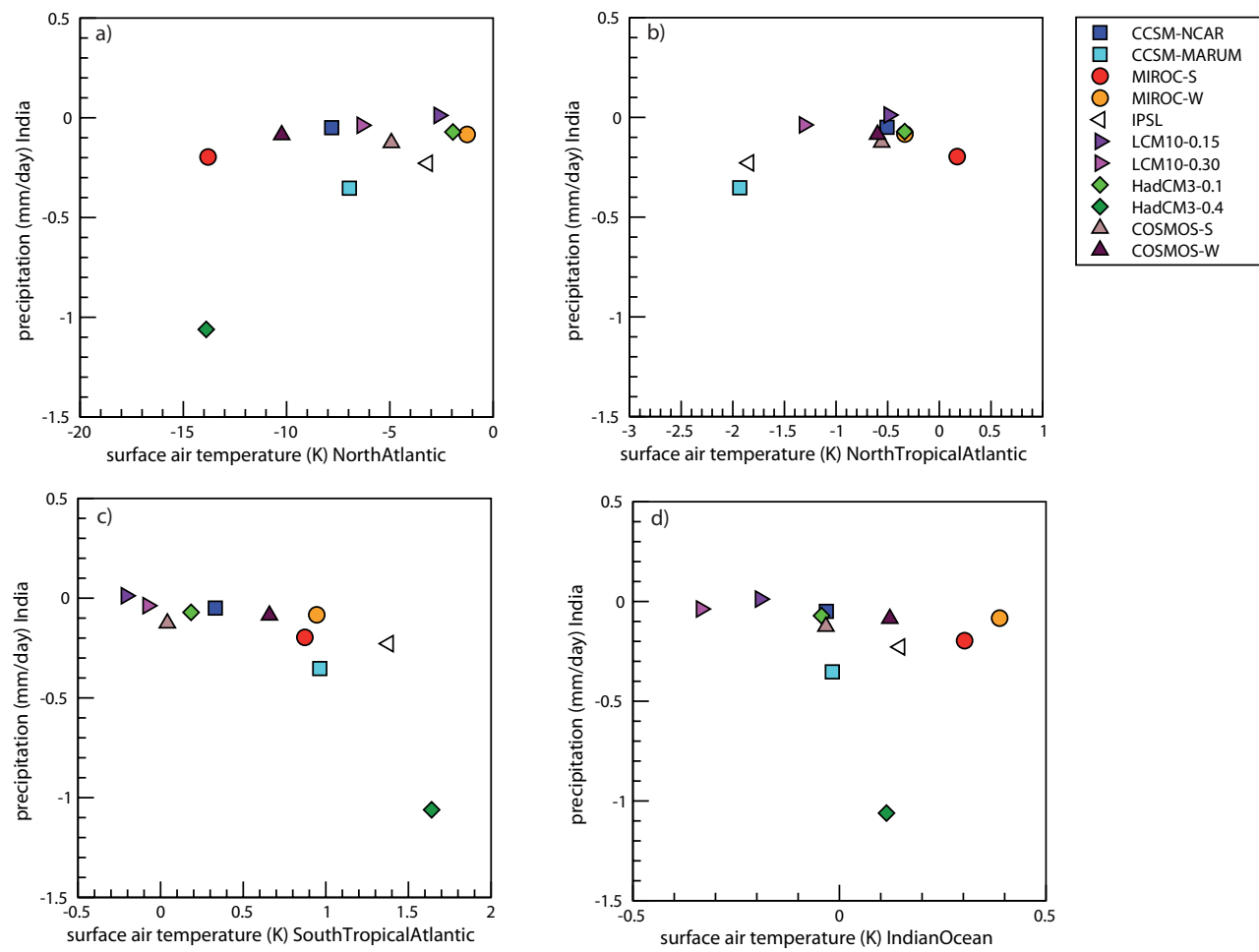

Fig. 10. Relationships involving precipitation changes over the Indian monsoon region, defined for latitudes ranging between 10 and $30^{\circ} \mathrm{N}$ and longitudes between 60 and $90^{\circ} \mathrm{E}$; (a) with the NorthAtlantic temperatures, (b) with the NorthTropicalAtlantic temperatures, (c) with the SouthTropicalAtlantic temperature and (d) with the IndianOcean temperatures. The "IndianOcean" region is defined for latitudes ranging between $10^{\circ} \mathrm{S}$ and $15^{\circ} \mathrm{N}$ and longitudes between 50 and $100^{\circ} \mathrm{E}$.

during Heinrich events, as briefly reviewed in Sect. 1. We do not find a consistent response over South East Asia, in terms of precipitation. This could be due to the rather simplified experimental set-ups used here and, in particular, to our not using Marine Isotopic Stage 3 (ca. 60-30 kyr BP) insolation, which would favour boreal summer insolation and, therefore, stronger Asian monsoons (Van Meerbeeck et al., 2009; Merkel et al., 2010; Kageyama et al., 2010). It could also be due to the Indian monsoon actually affecting the South East Asian monsoon records, as suggested from the modelling work of Pausata et al. (2011). Over these regions with consistent response, the amplitude of this response is, however, model dependent and more work is needed to finely compare model results to data, which would require more realistic boundary conditions. These results are qualitatively similar to those obtained for the preindustrial base state by Stouffer et al. (2006) with the exception of the behaviour over the northern Nordic Seas and the Arctic for which no model simulates a warming for the glacial base state.

- Regions with inconsistent behaviour include the Northeast Pacific, the southern ocean and especially Southeast Pacific and Antarctica. Even though some data are available for the Chilean coast and, of course, Antarctica, more data would help discriminating between models, hosing scenarios and mechanisms. A first distinction in the model responses refers to those simulating a weak AMOC decrease and those simulating a strong AMOC decrease. The former ones appear to transport the northern cooling to the southern ocean. Only the latter ones simulate a bi-polar see-saw. This bi-polar see-saw can then take a zonally symmetric or a zonally asymmetric form, hence, confirming the classification proposed by Clement and Peterson (2008). Indeed, those models which present a zonally symmetric response in the Southern Hemisphere generally also present a large cooling in the Northern Hemisphere extratropics. As far as this bi-polar see-saw is concerned, however, we must remain cautious in our comparison and conclusions since there could be differences in timing of the climatic response which we will have to investigate further.

- There is a relationship between local temperature and local precipitation changes over the North Atlantic and over the tropical Atlantic. But there are no obvious relationships between North Atlantic temperature changes and AMOC changes, nor between tropical 
Atlantic temperature/precipitation changes on the one hand, and AMOC or North Atlantic temperatures on the other hand. This suggests different extra-tropicaltropical teleconnection mechanisms in the different models.

- The African monsoon consistently decreases for all models, but it is difficult to relate the amount of precipitation decrease to temperature changes over the adjacent tropical Atlantic or to North Atlantic SST changes as suggested from the data presented by Niedermeyer et al. (2009). More analysis is required for this region at the seasonal level and it would be helpful to analyse atmospheric circulation changes in addition to the basic temperature and precipitation comparison presented here.

- The Indian monsoon weakening appears to be correlated both with North Atlantic and South Tropical Atlantic coolings. This suggests different teleconnection pathways for the different models. Here we would need specific sensitivity experiments to disentangle the response of the different models.

This comparison is, therefore, a first step in characterising and understanding the mechanisms at work in glacial fresh water hosing experiments. It is based on an ensemble of rather idealised experiments given the fact that most abrupt events occurred during the different background climate of MIS 3. We now need more specific sensitivity experiments to better understand each teleconnection, in the same way as has been performed for the present and for idealised geographical set-ups (cf. the review by Clement and Peterson, 2008).

Acknowledgements. M. K. thanks the University of Tokyo (AORI) for giving her the opportunity to start this work during her stay at AORI as invited professor in November 2010-January 2011. This work was then expanded and discussed following a number of conferences, in particular the INTIMATE workshop on deglaciation held in Copenhagen in November 2011. This work was also developed for the ERC TracSymbols project (FP7/20072013)/ERC grant agreement no. 249587). U. M. received funding through the DFG-Research Center/Excellence Cluster "The Ocean in the Earth System". A. A. acknowledges the support by the Environment Research and Technology Development Fund (S-10) of the Ministry of the Environment, Japan. G. L. and X. Z. received funding through the Helmholtz programmes PACES and REKLIM. B. L. O. acknowledges NCAR, sponsored by the US National Science Foundation (NSF), and the Climate Simulation Laboratory at NCAR's Computational and Information Systems Laboratory, which provided the computing resources.

Edited by: J. C. Hargreaves

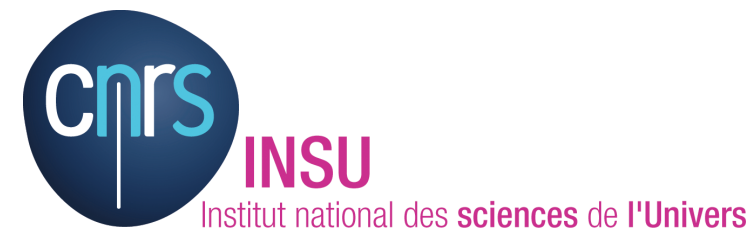

The publication of this article is financed by CNRS-INSU.

\section{References}

Blunier, T. and Brook, E. J.: Timing of millenial-scale climate change in Antarctica and Greenland during the last glacial period, Science, 291, 109-112, 2001.

Braconnot, P., Otto-Bliesner, B., Harrison, S., Joussaume, S., Peterchmitt, J.-Y., Abe-Ouchi, A., Crucifix, M., Driesschaert, E., Fichefet, Th., Hewitt, C. D., Kageyama, M., Kitoh, A., Laîné, A., Loutre, M.-F., Marti, O., Merkel, U., Ramstein, G., Valdes, P., Weber, S. L., Yu, Y., and Zhao, Y.: Results of PMIP2 coupled simulations of the Mid-Holocene and Last Glacial Maximum Part 1: experiments and large-scale features, Clim. Past, 3, 261277, doi:10.5194/cp-3-261-2007, 2007.

Buiron, D., Stenni, B., Chappellaz, J., Landais, A., Baumgartner, M., Bonazza, M., Capron, E., Frezzotti, M., Kageyama, M., Lemieux-Dudon, B., Masson-Delmotte, V., Parrenin, F., Schilt, A., Selmo, E., Severi, M., Swingedouw, D., and Udisti, R.: Regional imprints of millennial variability during the MIS 3 period around Antarctica, Quaternary Sci. Rev., 48, 99-112, 2012.

Chiang, J. C. H., Cheng, W., and Bitz, C. M.: Fast teleconnections to the tropical Atlantic sector from Atlantic thermohaline adjustment, Geophys. Res. Lett., 35, L07704, doi:10.1029/2008GL033292, 2008.

Chikamoto, M. O., Abe-Ouchi, A., Oka, A., Ohgaito, R., and Timmermann, A.: Quantifying the ocean's role in glacial $\mathrm{CO}_{2}$ reductions, Clim. Past, 8, 545-563, doi:10.5194/cp-8-545-2012, 2012.

Claussen, M., Mysak, L., Weaver, A., Crucifix, M., Fichefet, T., Loutre, M.-F., Weber, S., Alcamo, J., Alexeev, V., Berger, A., Calov, R., Ganopolski, A., Goosse, H., Lohmann, G., Lunkeit, F., Mokhov, I., Petoukhov, V., Stone, P., and Wang, Z.: Earth system models of intermediate complexity: Closing the gap in the spectrum of climate system models, Clim. Dynam., 15, 579-586, 2002.

Clement, A. C. and Peterson, L. C.: Mechanisms of abrupt climate change of the last glacial period, Rev. Geophys., 46, RG4002, doi:10.1029/2006RG000204, 2008.

Collins, W. D., Blackmon, M., Bitz, C. M., Bonan, G. B., Bretherton, C. S., Carton, J. A., Chang, P., Doney, S. C., Hack, J. J., Kiehl, J. T., Henderson, T., Large, W. G., McKenna, D., Santer, B. D., and Smith, R.: The Community Climate System Model: CCSM3, J. Climate, 19, 2122-2143, 2006.

Crowley, T. J.: North Atlantic deep water cools the Southern Hemisphere, Paleoceanography, 7, 489-497, 1992.

Dansgaard, W., Johnsen, S. J., Clausen, H. B., Dahl-Jensen, D., Gundestrup, N. S., Hammer, C. U., Hvidberg, C. S., Steffensen, J. P., Sveinbjörnsdottir, A. E., Jouzel, J., and Bond, G.: Evidence for general instability of past climate from a 250 -kyr ice-core record, Nature, 364, 218-220, 1993.

Dima, M. and Lohmann, G.: Evidence for Two Distinct Modes of Large-Scale Ocean Circulation Changes over the Last Century, 
J. Climate, 23, 5-16, 2010.

Driesschaert, E., Fichefet, T., Goosse, H., Huybrechts, P., Janssens, I., Mouchet, A., Munhoven, G., Brovkin, V., and Weber, S. L.: Modeling the influence of Greenland ice sheet melting on the Atlantic meridional overturning circulation during the next millennia, Geophys. Res. Lett., 34, L10707, doi:10.1029/2007GL029516, 2007.

Duplessy, J.-C., Roche, D. M., and Kageyama, M.: The Deep Ocean During the Last Interglacial Period, Science, 316, 89-91, doi:10.1126/science.1138582, 2007.

EPICA community members: One-to-one coupling of glacial climate variability in Greenland and Antarctica, Nature, 444, 195198, doi:10.1038/nature05301, 2006.

Ganopolski, A. and Rahmstorf, S.: Rapid changes of glacial climate simulated in a coupled climate model, Nature, 409, 153158, 2001.

Genty, D., Blamart, D., Ouahdi, R., Gilmour, M., Baker, A., Jouzel, J., and Van-Exter, S.: Precise dating of Dansgaard-Oeschger climate oscillations in western Europe from stalagmite data, Nature, 421, 833-937, 2003.

Gordon, C., Cooper, C., Senior, C., Banks, H., Gregory, J., Johns, T., Mitchell, J., and Wood, R.: The simulation of SST, sea ice extents and ocean heat transports in a version of the Hadley Centre coupled model without flux adjustments, Clim. Dynam., 16, 147-168, 2000.

Gregory, J. M., Dixon, K. W., Stouffer, R. J., Weaver, A. J., Driesschaert, E., Eby, M., Fichefet, T., Hasumi, H., Hu, A., Jungclaus, J. H., Kamenovitch, I. V., Levermann, A., Montoya, M., Murakami, S., Nawrath, S., Oka, A., Sokolov, A. P., and Thorpe, R. B.: A model intercomparison of changes in the Atlantic thermohaline circulation in response to increasing atmospheric $\mathrm{CO}_{2}$ concentration, Geophys. Res. Lett., 32, L12703, doi:10.1029/2005GL023209, 2005.

Heinrich, H.: Origin and consequences of cyclic ice rafting in the Northeast Atlantic ocean during the past 130000 years, Quaternary Res., 29, 142-152, 1988.

Jullien, E., Grousset, F., Malaize, B., Duprat, J., Sanchez-Goni, M. F., Eynaud, F., Charlier, K., Schneider, R., Bory, A., Bout, V., and Flores, J. A.: Low-latitude "dusty events" vs. high-latitude “icy Heinrich events”, Quaternary Res., 68, 379-386, 2007.

K-1 model developers: K-1 coupled model (MIROC) description, in: K-1 technical report, 1., edited by: Hasumi, H. and Emori, S., 34 pp., Center for climate system research, University of Tokyo, Japan, 2004.

Kageyama, M., Laîné, A., Abe-Ouchi, A., Braconnot, P., Cortijo, E., Crucifix, M., de Vernal, A., Guiot, J., Hewitt, C. D., Kitoh, A., Kucera, M., Marti, O., Ohgaito, R., Otto-Bliesner, B., Peltier, W. R., Vettoretti, G., Weber, S. L., and MARGO project members: Last Glacial Maximum temperatures over the North Atlantic, Europe and western Siberia: a comparison between PMIP models, MARGO sea-surface temperatures and pollen-based reconstructions, Quaternary Sci. Rev., 25, 2082-2102, 2006.

Kageyama, M., Mignot, J., Swingedouw, D., Marzin, C., Alkama, R., and Marti, O.: Glacial climate sensitivity to different states of the Atlantic Meridional Overturning Circulation: results from the IPSL model, Clim. Past, 5, 551-570, doi:10.5194/cp-5-5512009, 2009.

Kageyama, M., Paul, A., Roche, D. M., and van Meerbeeck, C. J.: Modelling glacial climatic millennial-scale variability related to changes in the Atlantic meridional overturning circulation: a review, Quaternary Sci. Rev., 29, 2931-2956, 2010.

Lenton, T. M., Marsh, R., Price, A. R., Lunt, D. J., Aksenov, Y., Annan, J. D., Cooper-Chadwick, T., Cox, S. J., Edwards, N. R., Goswami, S., Hargreaves, J. C., Harris, P. P., Jiao, Z., Livina, V. N., Payne, A. J., Rutt, I. C., Shepherd, J. G., Valdes, P. J., Williams, G., Williamson, M. S., and Yool, A.: Effects of atmospheric dynamics and ocean resolution on bi-stability of the thermohaline circulation examined using the Grid ENabled Integrated Earth system modelling (GENIE) framework, Clim. Dynam., 29, 591-613, doi:10.1007/s00382-007-0254-9, 2007.

Leuschner, D. C. and Sirocko, F.: The low-latitude monsoon climate during Dansgaard-Oeschger cycles and Heinrich Events, Quaternary Sci. Rev., 22, 925-941, 2000.

Manabe, S. and Stouffer, R. J.: Two stable equilibria of a coupled ocean-atmosphere model, J. Climate, 1, 841-866, 1988.

Manabe, S. and Stouffer, R. J.: Simulation of abrupt climate change induced by freshwater input to the North Atlantic Ocean, Nature, 378, 165-167, 1995.

Manabe, S. and Stouffer, R. J.: Coupled ocean-atmosphere model response to freshwater input: comparison to Younger Dryas event, Paleoceanography, 12, 321-336, 1997.

Marti, O., Braconnot, P., Dufresne, J.-L., Bellier, J., Benshila, R., Bony, S., Brockmann, P., Cadule, P., Caubel, A., Codron, F., de Noblet, N., Denvil, S., Fairhead, L., Fichefet, T., Foujols, M.A., Friedlingstein, P., Goosse, H., Grandpeix, J.-Y., Guilyardi, E., Hourdin, F., Idelkadi, A., Kageyama, M., Krinner, G., Lévy, C., Madec, G., Mignot, J., Musat, I., Swingedouw, D., and Talandier, C.: Key features of the IPSL ocean atmosphere model and its sensitivity to atmospheric resolution, Clim. Dynam., 34, 1-26, doi:10.1007/s00382-009-0640-6, 2010.

Marzin, C., Kallel, N., Kageyama, M., Duplessy, J.-C., and Braconnot, P.: Glacial fluctuations of the Indian monsoon and their relationship with North Atlantic abrupt climate change: new data and climate experiments, Clim. Past Discuss., 8, 6269-6308, doi:10.5194/cpd-8-6269-2012, 2012.

Merkel, U., Prange, M., and Schulz, M.: ENSO variability and teleconnections during glacial climates, Quaternary Sci. Rev., 29, 86-100, 2010.

Mignot, J. and Frankignoul, C.: Local and remote impacts of a tropical Atlantic salinity anomaly, Clim. Dynam., 35, 1133-1147, doi:10.1007/s00382-009-0621-9, 2010.

Mulitza, S., Prange, M., Stuut, J., Zabel, M., von Dobeneck, T., Itambi, A. C., Nizou, J., Schulz, M., and Wefer, G.: Sahel megadroughts triggered by glacial slowdowns of Atlantic meridional overturning, Paleoceanography, 23, PA4206, doi:10.1029/2008PA001637, 2008

Niedermeyer, E. M., Prange, M., Mulitza, S., Mollenhauer, G., Schefuss, E., and Schulz, M.: Extratropical forcing of Sahel aridity during Heinrich stadials, Geophys. Res. Lett., 36, L20707, doi:10.1029/2009GL039687, 2009.

Otto-Bliesner, B. L. and Brady, E. C.: The sensitivity of the climate response to the magnitude and location of freshwater forcing: last glacial maximum experiments, Quaternary Sci. Rev., 29, 56-73, doi:10.1016/j.quascirev.2009.07.004, 2010.

Otto-Bliesner, B. L., Hewitt, C. D., Marchitto, T. M., Brady, E., Abe-Ouchi, A., Crucifix, M., Murakami, S., and Weber, S. L.: Last Glacial Maximum ocean thermohaline circulation: PMIP2 model intercomparisons and data constraints, Geophys. Res. 
Lett., 34, L12706, doi:10.1029/2007GL029475, 2007.

Pausata, F. S. R., Battisti, D. S., Nisancioglu, K. H., and Bitz, C. M.: Chinese stalagmite $\delta^{18} O$ controlled by changes in the Indian monsoon during a simulated Heinrich event, Nat. Geosci., 4, 474-480, 2011.

Peterson, L. C., Haug, G. H., Hughen, K. A., and Röhl, U.: Rapid changes in the hydrologic cycle of the tropical North Atlantic during the last glacial, Science, 290, 1947-1951, 2000.

Pope, V., Gallani, M., Rowntree, P., and Stratton, R.: The impact of new physical parameterisations in the Hadley Centre climate model: HadAM3, Clim. Dynam., 16, 123-146, 2000.

Prange, M., Romanova, V., and Lohmann, G.: The glacial thermohaline circulation: stable or unstable?, Geophys. Res. Lett., 29, 2028, doi:10.1029/2002GL015337, 2002.

Rahmstorf, S.: Bifurcations of the Atlantic thermohaline circulation in response to changes in the hydrological cycle, Nature, 378, 145-149, 1995.

Renssen, H., Goosse, H., Crosta, X., and Roche, D. M.: Early Holocene Laurentide Ice Sheet deglaciation causes cooling in the high-latitude southern hemisphere through oceanic teleconnection, Paleoceanography, 25, PA3204, doi:10.1029/2009PA001854, 2010.

Roche, D., Paillard, D., and Cortijo, E.: Constraints on the duration and freshwater release of Heinrich event 4 through isotope modelling, Nature, 432, 379-382, 2004.

Roche, D. M., Wiersma, A. P., and Renssen, H.: A systematic study of the impact of freshwater pulses with respoect to different geographical locations, Clim. Dynam., 34, 997-1013, 2010.

Sánchez-Goñi, M.-F., Cacho, I., Turon, J.-L., Guiot, J., Sierro, F. J., Peypouquet, J.-P., Grimalt, J. O., and Shackleton, N. J.: Synchroneity between marine and terrestrial responses to millennial scale climatic variability during the last glacial period in the Mediterranean region, Clim. Dynam., 19, 95-105, 2002.

Singarayer, J. S. and Valdes, P. J.: High-latitude climate sensitivity to ice-sheet forcing over the last $120 \mathrm{kyr}$, Quaternary Sci. Rev., 29, 43-55, 2010.

Stocker, T. F. and Johnsen, S. J.: A minimum thermodynamic model for the bipolar seesaw, Paleoceanography, 18, 1087, doi:10.1029/2003PA000920, 2003.

Stommel, H. M.: Thermohaline convection with two stable regimes of flow, Tellus, 13, 224-230, 1961.

Stouffer, R. J., Yin, J., Gregory, J. M., Diwon, K. W., Spelman, M. J., Hurlin, W., Weaver, A. J., Eby, M., Flato, G. M., Hasumi, H., Hu, A., Jungclaus, J. H., Kamenovich, I. V., Levermann, A., Montoya, M., Murakami, S., Nawrath, S., Oka, A., Peltier, W. R., Robitaille, D. Y., Sokolov, A., Vettoretti, G., and Weber, S. L.: Investigating the causes of the response of the thermohaline circulation to past and future climate changes, J. Climate, 19, 13651387, 2006.
Swingedouw, D., Braconnot, P., and Marti, O.: Sensitivity of the Atlantic Meridional Overturning Circulation to the melting from northern glaciers in climate change experiments, Geophys. Res. Lett., 33, L07711, doi:10.1029/2006GL025765, 2006.

Swingedouw, D., Mignot, J., Braconnot, P., Mosquet, E., Kageyama, M., and Alkama, R.: Impact of freshwater release in the North Atlantic under different climate conditions in an OAGCM, J. Climate, 22, 6377-6403, 2009.

Van Meerbeeck, C. J., Renssen, H., and Roche, D. M.: How did Marine Isotope Stage 3 and Last Glacial Maximum climates differ? - Perspectives from equilibrium simulations, Clim. Past, 5, 33-51, doi:10.5194/cp-5-33-2009, 2009.

Voelker, A. H. L.: Global distribution of centennial-scale records for Marine Isotope Stage (MIS) 3: a database, Quaternary Sci. Rev., 21, 1185-1212, 2002.

Wang, X., Auler, A. S., Edwards, R. L., Cheng, H., Cristalli, P. S., Smart, P. L., Richards, D. A., and Shen, C.-C.: Wet periods in northeastern Brazil over the past $210 \mathrm{kyr}$ linked to distant climate anomalies, Nature, 432, 740-743, 2004.

Wang, Y. J., Cheng, H., Edwards, R. L., An, Z. S., Wu, J. Y., Shen, C.-C., and Dorale, J. A.: A high-resolution absolute-dated late Pleistocene monsoon record from Hulu Cave, China, Science, 294, 2345-2348, 2001.

Weaver, A. J., Sedláček, J., Eby, M., Alexander, K., Crespin, E., Fichefet, T., Philippon-Berthier, G., Joos, F., Kawamiya, M., Matsumoto, K., Steinacher, M., Tachiiri, K., Tokos, K., Yoshimori, M., and Zickfeld, K.: Stability of the Atlantic meridional overturning circulation: A model intercomparison, Geophys. Res. Lett., 39, L20709, doi:10.1029/2012GL053763, 2012.

Weber, S. L. and Drijfhout, S. S.: Stability of the Atlantic Meridional Overturning Circulation in the Last Glacial Maximum climate, Geophys. Res. Lett., 34, L22706, doi:10.1029/2007GL031437, 2007.

Wei, W. and Lohmann, G.: Simulated Atlantic Multidecadal Oscillation during the Holocene, J. Climate, 25, 6989-7002, doi:10.1175/JCLI-D-11-00667.1, 2012.

Yeager, S., Shields, C., Large, W., and Hack, J.: The low-resolution CCSM3, J. Climate, 19, 2545-2566, 2006.

Yin, J. and Stouffer, R. J.: Comparison of the Stability of the Atlantic Thermohaline Circulation in Two Coupled AtmosphereOcean General Circulation Models, J. Climate, 20, 4293-4315, 2007.

Zhang, X., Lohmann, G., Knorr, G., and Xu, X.: Two ocean states during the Last Glacial Maximum, Clim. Past Discuss., 8, 30153041, doi:10.5194/cpd-8-3015-2012, 2012. 